\title{
Numerical Analysis of Laminar Convective Condensation with the Presence of Noncondensable Gas Flowing Downward in a Vertical Channel
}

\author{
Mustapha Ait Hssain (D), Youness El Hammami, Rachid Mir, \\ Sara Armou, and Kaoutar Zine-Dine \\ Laboratory of Mechanics, Processes of Energy and Environment (LMPEE), National School of Applied Sciences, \\ Ibn Zohr, Agadir, Morocco \\ Correspondence should be addressed to Mustapha Ait Hssain; ait.hssain90@gmail.com
}

Received 19 February 2019; Accepted 2 June 2019; Published 20 June 2019

Academic Editor: Mostafa S. Shadloo

Copyright (c) 2019 Mustapha Ait Hssain et al. This is an open access article distributed under the Creative Commons Attribution License, which permits unrestricted use, distribution, and reproduction in any medium, provided the original work is properly cited.

\begin{abstract}
The purpose of this paper is to study and perform a numerical analysis of the simultaneous processes of mass and heat transfer during the condensation process of a steam in the existence of noncondensable gas (NCG) inside a descending vertical channel. In this study, the flow of the vapor-air mixture is laminar and the saturation conditions are prevailing at the inlet of the channel. The coupled control equations for liquid film, interfacial conditions, and mixture flow are solved together using the approach of finite volume. Detailed and valuable results are presented both in the liquid condensate film and in the mixing regions. These detailed results contain the dimensionless velocity and dimensionless temperature profiles in both phases, the dimensionless mass fraction of vapor, the axial variation of the dimensionless thickness of the film liquid $\delta^{*}$, and the accumulated condensate rate $M r$ as well the local Nusselt number $N u_{y}$. The relative humidity at the inlet varies from $60 \%$ to $100 \%$ and the inlet temperature from $40^{\circ} \mathrm{C}$ to $80^{\circ} \mathrm{C}$. The results confirm that a decrease in the mass concentration of NCG by the increasing the inlet relative humidity has a direct influence on the liquid film layer, the local number of Nusselt, and the variation of condensation rate accumulated through the channel. The results also designate that an increase of the inlet relative humidity and the inlet temperature ameliorates the condensation process. The comparison made for the coefficient of heat transfer due to condensation process and the condensate liquid film thickness with the literature results is in good concordance which gives more credibility to our calculation model.
\end{abstract}

\section{Introduction}

The process of condensation is frequently encountered in various applications such as in refrigeration, air-conditioning, chemical processing, and thermal energy production. As with many other applications, more efficient condensation heat transfer surfaces and more environment friendly heat transfer fluids have been the main focus of research and process improvement activities both in industrial and academic settings for several years. Hence the mastery of the transfer phenomenon in the condensation is needed for proper use and operation of energy in the condensing channels. The study of condensation problems is very complex for the reason that several parameters involved in the problems of flows with phase change. For this reason, the topic of liquid film condensation has taken much attention from different authors since the early years of the 19th century exactly with the works of Nusselt [1] until today. Hence, Nusselt [1] studied analytically the condensation of pure vapor inside a cold and vertical plate, based on the local equality between the viscous forces and the weight of the condensate film. His results indicated that the heat transfer in condensation depends on the local thickness of the liquid film. The topic of the present study is on numerical investigation of laminar liquid film condensation with cocurrent downward laminar vapor flow inside a vertical channel.

Thus, many researchers focused on the different aspects of condensation heat and mass transfer in channels and tubes for laminar flows. For instance, Dobran et al. [4] studied the case of condensation inside a vertical tube in the form of a 
laminar liquid film of pure vapor condensed on the walls. They modelled laminar downward flow in both the liquid film and the air-vapor mixture starting from the full governing equations. They obtained a set of regular differential equations by using an integral analysis and profile assumptions for the velocity in the liquid and in the vapor regions. They also supposed a fully developed inlet velocity profile and studied the effect of selected dimensionless variables. Le et al. [5, 6] adapted the Nusselt analysis for a cylindrical system. They established closed-form solutions for laminar film liquid thickness and heat transfer from a pure quiescent vapor on the inside and outside of a vertical curved wall. And the same authors [6] presented a theoretical analysis of film condensation for downward flow of a pure water vapor in a vertical tube. Lebedev et al. [2] reported experimental data finding of steam condensation by forced convection cooled on a flat plate in a channel with a longitudinal flow. They perceived that an intensification in the inlet relative humidity of the moist air leads to an intensification in heat transfer by condensation. These experimental results have become a reference result for validating numerical results of many numerical codes.

For laminar liquid condensation film from a gas-vapor mixture in a downward vertical tube, the authors [7-10] modelled numerical steadies for axisymmetric film condensation from an air-water vapor mixture with the presence of air as a NCG. Groff et al. [7] solved the governing differential equations for laminar liquid film and vapor flow by an implicit procedure. An iterative marching procedure was used to find the solution field results along the tube. They presented results concerning the effects of changing $\Delta T, P_{i n}, \mathrm{Re}_{i n}$ and the inlet air mass fraction. El-Hammami et al. [8] studied film condensation from water vapor-air mixture with small fraction of vapor in a downward vertical tube. The governing differential equations in both phases are solved using a finite difference discretization approach and the advection terms in the liquid, in axial momentum, and in temperature equations are neglected. They are based also on a marching iterative procedure to determine the profiles of temperature, velocity, vapor mass fraction, and liquid film thickness inside the tube. Hassaninejadfarahani et al. [9] extended the approach used by Groff et al. [7] to examine the steam-air flows with very high inlet gas mass concentration. They varied the $R H_{\text {in }}$ in a range of $30 \%$ to $100 \%$ and their $T_{\text {in }}$ in a range of $25^{\circ} \mathrm{C}$ to $90^{\circ} \mathrm{C}$. They found that the decrease in $R H_{\text {in }}$, which means increasing the amount of NCG, reduced greatly the rate of heat transfer. In addition, the thickness of the condensate liquid film increases with increasing $\mathrm{Re}_{i n}$, $\Delta T$, and $R H_{i n}$. In the same sense, Dharma Rao et al. [10] used an implicit finite difference method to solve momentum, energy, and diffusion equations in the mixture region. They based the mixture solution on the variation of vapor density rather than the NCG mass fraction and applied a condition of impermeability as an equation for the interface mass flow rate. Their model uses an iterative scheme for the interface temperature based on the energy balance at the interface.

The numerical simulation for the case of laminar liquid film condensation from a gas-vapor mixture in vertical channels has been discussed by $[3,11-13]$. Siow et al. $[11,12]$ modelled steady film laminar condensation from an air-water mixture and used a coupled implicit numerical approach to solve problems with a wide range of inlet concentration of air examined as a NCG. They established a two-phase, boundary-layer, and two-dimensional equation model for laminar liquid film condensation using a transformation of coordinates. They solved simultaneously the differential and nonlinear equations governing the flow for the whole system at each axial location using marching iterative scheme. In addition, constant pressure in the channel's cross-section was assumed and that axial diffusion of heat, momentum, and mass are negligible. They analyzed the effect of various operating parameters on the transfer during condensation in the presence of air as a NCG between the vertical [11] and inclined [12] channels. Dharma Rao et al. [13] also developed a model for convective laminar condensation of steam between vertical parallel plate channels in the existence of air as NCG. The focus of their research was on cases with high air concentration. They used the parabolic forms of the momentum, diffusion, and energy equations and used a finite difference method to resolve the equations with a marching scheme in all sections of the channel. The vapor density was used instead of the mass fraction of gas in their equations because, in condensation with a high gas mass concentration, the important and determining parameter is the variation of inlet relative humidity. Asis Giri et al. [3] studied a mixed convective heat transfer between two parallel walls using governing equation for both mixture phase and liquid phase under simultaneous heat and mass transfer representing the case of condensation on a parallel plate. A good agreement was found with the experimental data and numerical results. For this reason this model has been chosen as a reference to validate the numerical results of our current model.

Recently, numerical and experimental studies have been published concerning the condensation, among them Djamel Hammoudia et al. [14], Adil Charef et al. [15], Kaoutar Zinedine et al. [16, 17], which presented a numerical modelling of the condensation in a vertical channels and tubes during condensation by convection with the existence of NCGs. And Xiaomin Wu et al. [18] experimentally studied the heat transfer during condensation of a film by free convection on the outer surface of a horizontal tube in the presence of three NCGs. The results found in these studies confirm that the increase in $R H_{\text {in }} \mathrm{Re}_{\text {in }}$ and $T_{\text {in }}$ favors the condensation; on the other hand, the increase in the concentration of NCGs significantly reduced the heat transfer in condensation process.

The previous studies found in the literature reveal that the numerical study of heat and mass transfer for the condensation of a laminar liquid film from a vapor-gas mixture through a vertical channel by mixed convection, despite their practical importance in several sectors, has not been sufficiently studied. The present paper focuses on the study and analyzes the effects of different operating parameters and the characteristic of the flow on the coupled heat and mass transfer process for liquid film condensation through a downward flow along a symmetrically cooled vertical channel. In order to better understand the condensation process in different geometries we plan to extend our work 


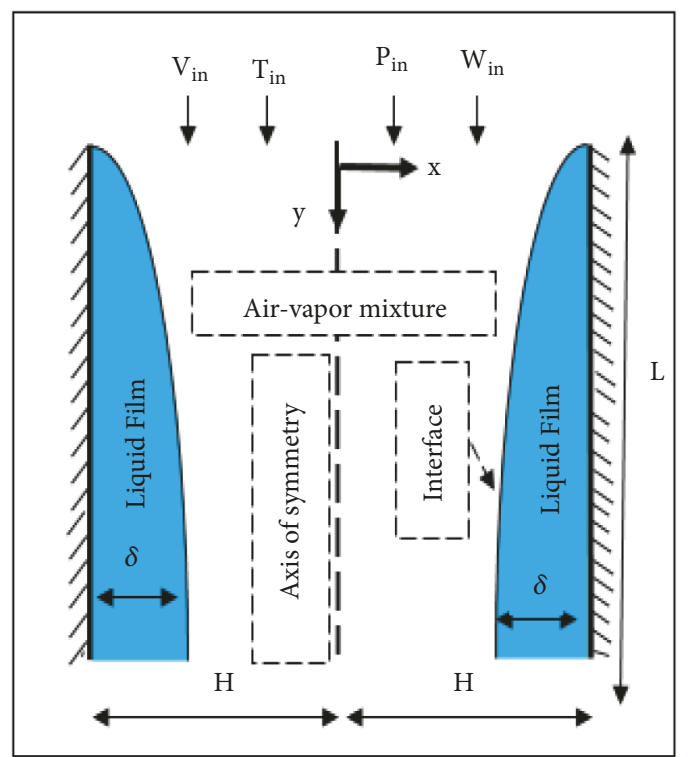

FIGURE 1: Schematic of the physical model study.

to other conduit geometries in the future. The reasons for selecting this geometry are as follows: (1) this geometry is relevant to some practical applications, (2) the flow can be treated as a two-dimensional problem that can be extended later to the case of flow inside vertical tubes, and (3) there are a few results available for laminar steady film condensation of vapor-air mixtures inside vertical channels.

\section{Mathematical Formulation and Physical Model}

We consider a gas mixture flowing inside a vertical channel width having a length $\mathrm{L}$ maintain a distance $2 \mathrm{H}$. This forms a parallel plate channel, which is symmetric about the midplan. The thick condensate Figure 1 is subjected to the action of gravitational forces, pressure, and friction at the interface between liquid and vapor regions. The walls of the vertical channel are supposed to be isothermal. At the entrance of the channel, comes a hot gas-steam mixture to flow at a uniform temperature $T_{\text {in }}$, velocity $V_{\text {in }}$, pressure $P_{\text {in }}$, and mass fraction of water vapor $\mathrm{W}_{\text {in }}$. The Cartesian coordinate system employed is shown at the top of Figure 1. The y-direction is measured downwards, while the $\mathrm{x}$-direction is measured perpendicular to the $\mathrm{y}$-direction and directed to the right vertical plate. A refined grid is used near of the interface and the symmetry line and near the walls.

(a) The gas flow is laminar and stationary.

(b) The problematic studied in this article is supposed to be two-dimensional.

(c) The vapor-air mixture is considered as an ideal mixture of water vapor and dry air.

(d) Pressure forces effects in the liquid phase are neglected. (e) The viscous dissipation, the radiation heat transfer, and the pressure work terms are neglected in the energy equation.

2.1. Liquid Region. It is expected that the thickness of the liquid condensate is relatively small compared to the phase of the mixture as the liquid film speeds are smaller than with respect to the mixture phase. Since the liquid flowing down is primarily due to the buoyant force, then, owing to the assumptions cited above, we have the equations of the conservation of mass, momentum, and energy, respectively:

$$
\begin{aligned}
& \frac{\partial}{\partial x^{*}}\left(\rho_{L} u_{L}^{*}\right)+\frac{\partial}{\partial y^{*}}\left(\rho_{L} v_{L}^{*}\right)=0 \\
& \frac{\partial}{\partial x^{*}}\left(\rho_{L} u_{L}^{*} u_{L}^{*}\right)+\frac{\partial}{\partial y^{*}}\left(\rho_{L} v_{L}^{*} u_{L}^{*}\right) \\
& \quad=\frac{\partial}{\partial x^{*}}\left(\frac{\mu_{L}}{V_{i n} H} \frac{\partial u_{L}^{*}}{\partial x^{*}}\right)+\frac{\partial}{\partial y^{*}}\left(\frac{\mu_{L}}{V_{i n} H} \frac{\partial u_{L}^{*}}{\partial y^{*}}\right) \\
& \frac{\partial}{\partial x^{*}}\left(\rho_{L} u_{L}^{*} v_{L}^{*}\right)+\frac{\partial}{\partial y^{*}}\left(\rho_{L} v_{L}^{*} v_{L}^{*}\right) \\
& \quad=\frac{\partial}{\partial x^{*}}\left(\frac{\mu_{L}}{V_{i n} H} \frac{\partial v_{L}^{*}}{\partial x^{*}}\right)+\frac{\partial}{\partial y^{*}}\left(\frac{\mu_{L}}{V_{i n} H} \frac{\partial v_{L}^{*}}{\partial y^{*}}\right)+\frac{g \rho_{L} H}{V_{i n}^{2}} \\
& \frac{\partial}{\partial x^{*}}\left(\rho_{L} C_{P L} u_{L}^{*} T_{L}^{*}\right)+\frac{\partial}{\partial y^{*}}\left(\rho_{L} C_{P L} v_{L}^{*} T_{L}^{*}\right) \\
& \quad=\frac{\partial}{\partial x^{*}}\left(\frac{\lambda_{L}}{V_{i n} H} \frac{\partial T_{L}^{*}}{\partial x^{*}}\right)+\frac{\partial}{\partial y^{*}}\left(\frac{\lambda_{L}}{V_{i n} H} \frac{\partial T_{L}^{*}}{\partial y^{*}}\right)
\end{aligned}
$$

2.2. Mixture Region. To formulate the governing conservation equations in the mixture domain, we have supposed that the flow is steady and laminar in both phases and that 
the liquid and mixture are Newtonian fluids. The vapor-gas mixture was considered to be an ideal-gas mixture and the saturation conditions were supposed at the liquid-mixture interface. Then, the governing equations of mass conservation, momentum, energy, and diffusion, respectively, in the mixture region are expressed as follows:

$$
\begin{aligned}
& \frac{\partial}{\partial x^{*}}\left(\rho_{M} u_{M}^{*}\right)+\frac{\partial}{\partial y^{*}}\left(\rho_{M} v_{M}^{*}\right)=0 \\
& \frac{\partial}{\partial x^{*}}\left(\rho_{M} u_{M}^{*} u_{M}^{*}\right)+\frac{\partial}{\partial y^{*}}\left(\rho_{M} v_{M}^{*} u_{M}^{*}\right) \\
& =-\rho_{\text {in }} \frac{\partial P_{M}^{*}}{\partial x^{*}} \\
& +\left[\frac{\partial}{\partial x^{*}}\left(\frac{\mu_{M}}{V_{i n} H} \frac{\partial u_{M}^{*}}{\partial x^{*}}\right)+\frac{\partial}{\partial y^{*}}\left(\frac{\mu_{M}}{V_{\text {in }} H} \frac{\partial u_{M}^{*}}{\partial y^{*}}\right)\right] \\
& \frac{\partial}{\partial x^{*}}\left(\rho_{M} u_{M}^{*} v_{M}^{*}\right)+\frac{\partial}{\partial y^{*}}\left(\rho_{M} v_{M}^{*} v_{M}^{*}\right) \\
& =-\rho_{\text {in }} \frac{\partial P_{M}^{*}}{\partial y^{*}}+\frac{\partial}{\partial x^{*}}\left(\frac{\mu_{M}}{V_{\text {in }} H} \frac{\partial v_{M}^{*}}{\partial x^{*}}\right) \\
& +\frac{\partial}{\partial y^{*}}\left(\frac{\mu_{M}}{V_{\text {in }} H} \frac{\partial v_{M}^{*}}{\partial y^{*}}\right)+\frac{g \rho_{M} H}{V_{\text {in }}^{2}} \\
& \frac{\partial}{\partial x^{*}}\left(\rho_{M} C_{P M} u_{M}^{*} T_{M}^{*}\right)+\frac{\partial}{\partial y^{*}}\left(\rho_{M} C_{P M} v_{M}^{*} T_{M}^{*}\right) \\
& =\frac{\partial}{\partial x^{*}}\left(\frac{\lambda_{M}}{V_{\text {in }} H} \frac{\partial T_{M}^{*}}{\partial x^{*}}\right)+\frac{\partial}{\partial y^{*}}\left(\frac{\lambda_{M}}{V_{i n} H} \frac{\partial T_{M}^{*}}{\partial y^{*}}\right) \\
& +\frac{\partial}{\partial x^{*}}\left[\frac{\rho_{M} D}{V_{\text {in }} H}\left(C_{P V}-C_{P a}\right) \frac{\partial W}{\partial x^{*}} T_{M}^{*}\right] \\
& \frac{\partial}{\partial x^{*}}\left(\rho_{M} u_{M}^{*} W\right)+\frac{\partial}{\partial y^{*}}\left(\rho_{M} v_{M}^{*} W\right) \\
& =\frac{\partial}{\partial x^{*}}\left(\frac{\rho_{M} D}{V_{i n} H} \frac{\partial W}{\partial x^{*}}\right)+\frac{\partial}{\partial y^{*}}\left(\frac{\rho_{M} D}{V_{i n} H} \frac{\partial W}{\partial y^{*}}\right)
\end{aligned}
$$

2.3. Coordinate Transformation for Both Phases. A change of variable is necessary to show the liquid film thickness in the governing equations by transforming the coordinate variables $(x, y)$ to the coordinates $(\chi, \eta)$ as follows:

For all the y-axis,

$$
y=\chi
$$

For $0 \leq x \leq \delta$,

$$
\eta=\frac{x}{\delta}
$$

For $\delta \leq x \leq H$,

$$
\eta=\frac{x-\delta}{H-\delta}+1
$$

Thus, governing equations (1)-(4) of liquid domain after using the transforming coordinate are written in the following ways.

(i) Continuity equation is

$$
\frac{\partial}{\partial \eta}\left[\rho_{L} u_{L}^{*}-\eta \frac{\partial \delta^{*}}{\partial \chi} \rho_{L} v_{L}^{*}\right]+\frac{\partial\left(\rho_{L} \delta^{*} v_{L}^{*}\right)}{\partial \chi}=0
$$

(ii) Momentum equation is

$$
\begin{gathered}
\frac{\partial\left(\rho_{L} u_{L}^{*} u_{L}^{*}\right)}{\partial \eta}+\frac{\partial\left(\rho_{L} u_{L}^{*} \delta^{*} v_{L}^{*}\right)}{\partial \chi}=\frac{\partial}{\partial \eta}\left(\frac{\mu_{L}}{\delta^{*} V_{i n} H} \frac{\partial u_{L}^{*}}{\partial \eta}\right) \\
+\frac{\partial}{\partial \chi}\left(\frac{\delta^{*} \mu_{L}}{V_{i n} H} \frac{\partial u_{L}^{*}}{\partial \chi}\right)-\left(\frac{\partial \delta^{*}}{\partial \chi}\right) \\
\cdot\left[\frac{\mu_{L}}{V_{i n} H}\left(\frac{\partial u_{L}^{*}}{\partial \chi}-\frac{\eta}{\delta^{*}} \frac{\partial \delta^{*}}{\partial \chi} \frac{\partial u_{L}^{*}}{\partial \eta}\right)\right. \\
\left.+\eta \frac{\partial}{\partial \chi}\left(\frac{\mu_{L}}{V_{i n} H} \frac{\partial u_{L}^{*}}{\partial \eta}\right)\right]+\frac{\partial}{\partial \eta}\left[\eta \frac{\partial \delta^{*}}{\partial \chi} \rho_{L} v_{L}^{*} u_{L}^{*}\right] \\
\frac{\partial\left(\rho_{L} v_{L}^{*} u_{L}^{*}\right)}{\partial \eta}+\frac{\partial\left(\rho_{L} v_{L}^{*} \delta^{*} v_{L}^{*}\right)}{\partial \chi}=\frac{\partial}{\partial \eta}\left(\frac{\mu_{L}}{\delta^{*} V_{i n} H} \frac{\partial v_{L}^{*}}{\partial \eta}\right) \\
+\frac{\partial}{\partial \chi}\left(\frac{\delta^{*} \mu_{L}}{V_{i n} H} \frac{\partial v_{L}^{*}}{\partial \chi}\right)+\frac{\partial}{\partial \eta}\left[\eta \frac{\partial \delta^{*}}{\partial \chi} \rho_{L} v_{L}^{*} v_{L}^{*}\right] \\
+\left(\frac{\partial \delta^{*}}{\partial \chi}\right)\left[\frac{\mu_{L}}{V_{i n} H}\left(\frac{\partial v_{L}^{*}}{\partial \chi}-\frac{\eta}{\delta^{*}} \frac{\partial \delta^{*}}{\partial \chi} \frac{\partial v_{L}^{*}}{\partial \eta}\right)\right. \\
\left.+\eta \frac{\partial}{\partial \chi}\left(\frac{\mu_{L}}{V_{i n} H} \frac{\partial v_{L}^{*}}{\partial \eta}\right)\right]+\frac{\rho_{L} g \delta^{*} H}{V_{i n}^{2}}
\end{gathered}
$$

(iii) Energy equation is

$$
\begin{aligned}
& \frac{\partial\left(\rho_{L} C_{P L} u_{L}^{*} T_{L}\right)}{\partial \eta}+\frac{\partial\left(\rho_{L} C_{P L} \delta^{*} v_{L}^{*} T_{L}\right)}{\partial \chi} \\
& =\frac{\partial}{\partial \eta}\left(\frac{\lambda_{L}}{\delta^{*} V_{i n} H} \frac{\partial T_{L}^{*}}{\partial \eta}\right)+\frac{\partial}{\partial \chi}\left(\frac{\delta^{*} \lambda_{L}}{V_{i n} H} \frac{\partial T_{L}^{*}}{\partial \chi}\right) \\
& -\left(\frac{\partial \delta^{*}}{\partial \chi}\right)\left[\frac{\lambda_{L}}{V_{i n} H}\left(\frac{\partial T_{L}^{*}}{\partial \chi}-\frac{\eta}{\delta^{*}} \frac{\partial \delta^{*}}{\partial \chi} \frac{\partial T_{L}^{*}}{\partial \eta}\right)\right. \\
& \left.+\eta \frac{\partial}{\partial \chi}\left(\frac{\lambda_{L}}{V_{i n} H} \frac{\partial T_{L}^{*}}{\partial \eta}\right)\right]+\frac{\partial}{\partial \eta}\left[\eta \frac{\partial \delta^{*}}{\partial \chi} \rho_{L} C_{P L} v_{L}^{*} T_{L}^{*}\right]
\end{aligned}
$$

The mass, momentum, and energy balance equations for the gas phase and the diffusion equation for the vapor species are shown as follows.

(iv) Continuity equation is

$$
\begin{gathered}
\frac{\partial}{\partial \eta}\left[\rho_{M} u_{M}^{*}-(2-\eta) \frac{\partial \delta^{*}}{\partial \chi} \rho_{M} v_{M}^{*}\right] \\
+\frac{\partial\left(\left(1-\delta^{*}\right) \rho_{M} v_{M}^{*}\right)}{\partial \chi}=0
\end{gathered}
$$


(v) Momentum equation is

$$
\begin{aligned}
& \frac{\partial\left(\rho_{M} u_{M}^{*} u_{M}^{*}\right)}{\partial \eta}+\frac{\partial\left(\left(1-\delta^{*}\right) \rho_{M} u_{M}^{*} v_{M}^{*}\right)}{\partial \chi}=-\rho_{i n} \frac{\partial P_{M}^{*}}{\partial \eta} \\
& +\frac{\partial}{\partial \eta}\left(\frac{\mu_{M}}{\left(1-\delta^{*}\right) V_{i n} H} \frac{\partial u_{M}^{*}}{\partial \eta}\right) \\
& +\frac{\partial}{\partial \chi}\left(\frac{\left(1-\delta^{*}\right) \mu_{M}}{V_{i n} H} \frac{\partial u_{M}^{*}}{\partial \chi}\right)+\left(\frac{\partial \delta^{*}}{\partial \chi}\right) \\
& \cdot\left[\frac{\mu_{M}}{V_{i n} H}\left(\frac{\partial u_{M}^{*}}{\partial \chi}-\frac{2-\eta}{1-\delta^{*}} \frac{\partial \delta^{*}}{\partial \chi} \frac{\partial u_{M}^{*}}{\partial \eta}\right)\right. \\
& \left.-(2-\eta) \frac{\partial}{\partial \chi}\left(\frac{\mu_{M}}{V_{i n} H} \frac{\partial u_{M}^{*}}{\partial \eta}\right)\right] \\
& +\frac{\partial}{\partial \eta}\left[(2-\eta) \frac{\partial \delta^{*}}{\partial \chi} \rho_{M} v_{M}^{*} u_{M}^{*}\right] \\
& \frac{\partial\left(\rho_{M} v_{M}^{*} u_{M}^{*}\right)}{\partial \eta}+\frac{\partial\left(\left(1-\delta^{*}\right) \rho_{M} v_{M}^{*} v_{M}^{*}\right)}{\partial \chi} \\
& =-\frac{\partial}{\partial \chi}\left(\rho_{\text {in }}\left(1-\delta^{*}\right) P_{M}^{*}\right) \\
& +\frac{\partial}{\partial \eta}\left(\frac{\partial \delta^{*}}{\partial \chi}(2-\eta) \rho_{i n} P_{M}^{*}\right) \\
& +\left[\frac{\partial}{\partial \eta}\left(\frac{\mu_{M}}{\left(1-\delta^{*}\right) V_{i n} H} \frac{\partial v_{M}^{*}}{\partial \eta}\right)\right. \\
& \left.+\frac{\partial}{\partial \chi}\left(\frac{\left(1-\delta^{*}\right) \mu_{M}}{V_{i n} H} \frac{\partial v_{M}^{*}}{\partial \chi}\right)\right]+\frac{g \rho_{M}\left(1-\delta^{*}\right) H}{V_{i n}^{2}} \\
& +\frac{\partial}{\partial \eta}\left[(2-\eta) \frac{\partial \delta^{*}}{\partial \chi} \rho_{M} v_{M}^{*} v_{M}^{*}\right]+\left(\frac{\partial \delta^{*}}{\partial \chi}\right) \\
& \cdot\left[\frac{\mu_{M}}{V_{i n} H}\left(\frac{\partial v_{M}^{*}}{\partial \chi}-\frac{2-\eta}{1-\delta^{*}} \frac{\partial \delta^{*}}{\partial \chi} \frac{\partial v_{M}^{*}}{\partial \eta}\right)\right. \\
& \left.-(2-\eta) \frac{\partial}{\partial \chi}\left(\frac{\mu_{M}}{V_{i n} H} \frac{\partial v_{M}^{*}}{\partial \eta}\right)\right]
\end{aligned}
$$

(vi) Energy equation is

$$
\begin{gathered}
\frac{\partial\left(\rho_{M} C_{P M} u_{M}^{*} T_{M}^{*}\right)}{\partial \eta}+\frac{\partial\left(\left(1-\delta^{*}\right) \rho_{M} C_{P M} v_{M}^{*} T_{M}^{*}\right)}{\partial \chi} \\
=\frac{\partial}{\partial \eta}\left(\frac{\lambda_{M}}{\left(1-\delta^{*}\right) V_{i n} H} \frac{\partial T_{M}^{*}}{\partial \eta}\right) \\
+\frac{\partial}{\partial \chi}\left(\frac{\left(1-\delta^{*}\right) \lambda_{M}}{V_{i n} H} \frac{\partial T_{M}^{*}}{\partial \chi}\right)+\left(\frac{\partial \delta^{*}}{\partial \chi}\right) \\
\cdot\left[\frac{\lambda_{M}}{V_{i n} H}\left(\frac{\partial T_{M}^{*}}{\partial \chi}-\frac{2-\eta}{1-\delta^{*}} \frac{\partial \delta^{*}}{\partial \chi} \frac{\partial T_{M}^{*}}{\partial \eta}\right)\right.
\end{gathered}
$$

$$
\begin{aligned}
& \left.-(2-\eta) \frac{\partial}{\partial \chi}\left(\frac{\lambda_{M}}{V_{i n} H} \frac{\partial T_{M}^{*}}{\partial \eta}\right)\right] \\
& +\frac{\partial}{\partial \eta}\left[(2-\eta) \frac{\partial \delta^{*}}{\partial \chi} \rho_{M} C_{P M} v_{M}^{*} T_{M}^{*}\right] \\
& +\frac{\partial}{\partial \eta}\left[\frac{\rho_{M} D\left(C_{P V}-C_{P a}\right)}{\left(1-\delta^{*}\right) V_{i n} H}\left(T_{M}^{*} \frac{\partial W}{\partial \eta}+\frac{T_{W}}{\Delta T} \frac{\partial W}{\partial \eta}\right)\right]
\end{aligned}
$$

(vii) Diffusion equation is

$$
\begin{aligned}
& \frac{\partial\left(\rho_{M} u_{M}^{*} W\right)}{\partial \eta}+\frac{\partial\left((H-\delta) \rho_{M} v_{M}^{*} W\right)}{\partial \chi} \\
& =\frac{\partial}{\partial \eta}\left(\frac{\rho_{M} D}{\left(1-\delta^{*}\right) V_{i n} H} \frac{\partial W}{\partial \eta}\right) \\
& +\frac{\partial}{\partial \chi}\left(\frac{\rho_{M} D\left(1-\delta^{*}\right)}{V_{i n} H} \frac{\partial W}{\partial \chi}\right)+\left(\frac{\partial \delta^{*}}{\partial \chi}\right) \\
& .\left[\frac{\rho_{M} D}{V_{i n} H}\left(\frac{\partial W}{\partial \chi}-\frac{2-\eta}{1-\delta^{*}} \frac{\partial \delta^{*}}{\partial \chi} \frac{\partial W}{\partial \eta}\right)\right. \\
& \left.-(2-\eta) \frac{\partial}{\partial \chi}\left(\frac{\rho_{M} D}{V_{i n} H} \frac{\partial W}{\partial \eta}\right)\right] \\
& +\frac{\partial}{\partial \eta}\left[(2-\eta) \frac{\partial \delta^{*}}{\partial \chi} \rho_{M} v_{M}^{*} W\right]
\end{aligned}
$$

(viii) Boundary conditions are as follows.

The boundary and the inlet conditions in transformed coordinate are expressed below.

$$
\begin{aligned}
& \text { At the wall } \eta=0 \text { : } \\
& u_{L}=0 \text {; } \\
& v_{L}=0 \text {; } \\
& T_{L}=T_{W}
\end{aligned}
$$

At the inlet $\chi=0$ :

$$
\begin{aligned}
u_{M} & =0 ; \\
v_{M} & =u_{i n} ; \\
T_{M} & =T_{i n} ; \\
W & =W_{i n}
\end{aligned}
$$

At the interface $\eta=1$ :

$$
\begin{aligned}
& u_{L, \text { int }}=u_{\mathrm{M}, \text { int }} \\
& \left.\frac{\mu_{L}}{\delta} \frac{\partial v_{L}}{\partial \eta}\right|_{\text {int }}=\left.\frac{\mu_{M}}{H-\delta} \frac{\partial v_{M}}{\partial \eta}\right|_{\text {int }} \\
& \left.\frac{\lambda_{L}}{\delta} \frac{\partial T_{L}}{\partial \eta}\right|_{\text {int }}=\left.\frac{\lambda_{M}}{H-\delta} \frac{\partial T_{M}}{\partial \eta}\right|_{\text {int }}-J_{\text {int }}^{\prime \prime} h_{f g} ; \\
& T_{L, \text { int }}=T_{M, \text { int }}=T_{\text {sat }}
\end{aligned}
$$




$$
\begin{aligned}
& J_{\text {int }}^{\prime \prime}=-\left.\frac{\rho_{M} D}{(H-\delta)\left(1-W_{\text {int }}\right)} \frac{\partial W}{\partial \eta}\right|_{\text {int }} \\
& \rho_{L, \text { int }}\left(u_{L, \text { int }}-v_{L, \text { int }} \frac{d \delta}{d \chi}\right)=\rho_{M, \text { int }}\left(u_{M, \text { int }}-v_{M, \text { int }} \frac{d \delta}{d \chi}\right) \\
&=J_{\text {int }}^{\prime \prime}
\end{aligned}
$$

At the axis of symmetry $\eta=2$ :

$$
\begin{gathered}
\frac{\partial v_{M}}{\partial \eta}=0 ; \\
\frac{\partial T_{M}}{\partial \eta}=0 ; \\
\frac{\partial W}{\partial \eta}=0 ; \\
u_{M}=0 ;
\end{gathered}
$$

2.4. Inlet Air Mass Fraction Specification. In condensation models of gas-vapor mixtures that are not applied to humid air conditions, saturation conditions are assumed at the channel inlet. In this case, it is sufficient to specify the inlet pressure and the inlet gas mass concentration. Then, the inlet partial pressure of the steam is calculated from

$$
\frac{P_{V, \text { in }}}{P_{\text {in }}}=\frac{\left(1-W_{\text {in }}\right)}{\left(1-W_{\text {in }}\left[1-\left(M_{V} / M_{a}\right)\right]\right)}
$$

For water and air, the ratio of the molar masses of vapor and gas $M_{V} / M_{a}=0.62185 . T_{\text {in }}$ is supposed to be equal to the saturation temperature for the partial pressure of the vapor. This corresponds to a relative humidity of $100 \%$.

When the inlet flow is steam-air mixture, $T_{i n}$ is specified added to $P_{\text {in }}$. In this case, the inlet NCG which is air in this case is computed from $R H_{i n}, P_{i n}$, and $T_{i n}$ as follows. The water content in the air is given by the specific humidity. Therefore, for the water vapor and air mixture, the specific humidity is related to the total pressure $\mathrm{P}$, and the partial pressure of the vapor $P_{v}$

$$
\omega_{\text {in }}=\left(\frac{M_{V}}{M_{a}}\right) \frac{P_{V, \text { in }}}{\left(P_{\text {in }}-P_{V, \text { in }}\right)}
$$

The relative humidity at the inlet is expressed as follows:

$$
R H_{\text {in }}=\frac{P_{V, \text { in }}}{\left(P_{V, \text { sat }}\right)_{\text {in }}}
$$

The inlet air mass fraction is computed from the inlet relative humidity, inlet pressure, and inlet temperature via $\left(P_{V \text {,sat }}\right)_{\text {in }}$ using

$$
W_{\text {in }}=\frac{\left(P_{\text {in }}-R H_{\text {in }}\left(P_{V, \text { sat }}\right)_{\text {in }}\right)}{\left(P_{\text {in }}-R H_{\text {in }}\left(P_{V, \text { sat }}\right)_{\text {in }}\left[1-\left(M_{V} / M_{a}\right)\right]\right)}
$$

The mass fraction at the interface can be calculated using

$$
W_{i}=P_{V, i} \times \frac{M_{V}}{\left(P_{V, i} M_{V}+\left(P-P_{V, i}\right) M_{a}\right)}
$$

(i) Heat balance at the interface implys

$$
\left[-\lambda_{L} \frac{\partial T_{L}}{\partial x}\right]_{L, \text { int }}=\left[-\lambda_{M} \frac{\partial T_{M}}{\partial x}\right]_{M, \text { int }}+J_{\text {int }}^{\prime \prime} h_{f g}
$$

Since the problem studied here is a condensation process, it is therefore necessary to pay particular attention to heat and mass transfer due to this phenomenon of phase change. The local heat exchange between the air-vapor mixture flow and the channel wall is mathematically written as follows.

As a reasonable approximation for a thin film with a linear temperature profile, the local Nusselt number could be taken as

$$
N u_{y}=\frac{2 H\left(T_{\text {int }}-T_{W}\right)}{\delta\left(T_{\text {in }}-T_{W}\right)}=\frac{2\left(T_{\text {int }}-T_{W}\right)}{\delta^{*}\left(T_{\text {in }}-T_{W}\right)}
$$

(ii) Accumulated condensate rate is

$$
M r=\frac{\int_{0}^{y} J_{\text {int }}^{\prime \prime} d y}{\dot{m}_{\text {in }}}
$$

\section{Numerical Solution Method}

3.1. Computational Grid and Discretization. The governing equations transformed into coordinates $(\chi, \eta)$ of both liquid and gas phases became rectangular as shown in Figure 1. Therefore, the variable position of the interface becomes a perfectly vertical straight line and parallel to the wall because of the coordinate transformation performed. An unstructured computational grid with rectangular control volumes was used. The distribution of the nodes throughout the channel varies to obtain a suitable refinement in the liquid region close to the cold wall and close to the interface as well as at the inlet of the channel; in the same way in the region of the vapor-gas mixture the mesh is thinner close to the interface, the axis of symmetry, and the entry of the channel as presented previously in Figure 2.

3.2. Condensate Film Thickness. The condensate film thickness evolution is determined from the energy balance equation performed at the interface, as given by

$$
\begin{aligned}
\frac{\lambda_{L}}{\delta}\left(\frac{\partial T_{L}}{\partial \eta}\right)_{\mathrm{int}}= & \frac{\lambda_{M}}{H-\delta}\left(\frac{\partial T_{M}}{\partial \eta}\right)_{\mathrm{int}} \\
& +h_{f g} \frac{d}{d \chi} \int_{0}^{1} \rho_{L} u_{L} \delta d \eta
\end{aligned}
$$

This equation is discretized as in the work of Chin [19] and by multiplying the members of the equation (see (38)) by $\delta(H-$ $\delta$ ) we obtain a polynomial of third order which is solved using Newton-Raphson iterative method.

3.3. Numerical Solution Procedure. The discretization of the partial differential governing equations and the boundarylayer conditions were done using the approach of finite volume. The coupled convection and diffusion equations are solved by using a power scheme developed by Patankar [20]. 


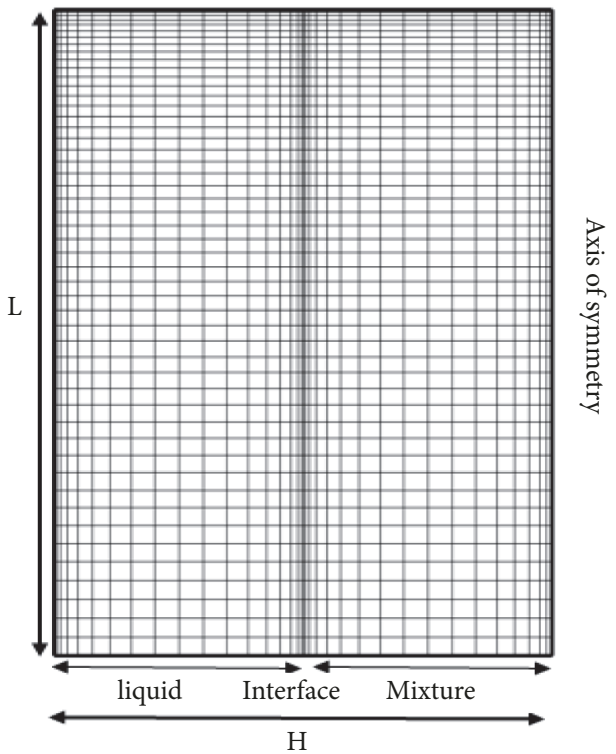

Figure 2: Mesh system.

After discretization, the obtained tridiagonal system associated with the boundary-layer conditions and the interface are solved together using the Thomas algorithm and, for the speed-pressure coupling, we use the SIMPLE algorithm because it is the most universal and the most used in incompressible flow problems [20]. The numerical solution aforementioned has been successfully implemented in an inhouse computer code and computations were performed in double precision. A language FORTRAN code was developed to simulate and calculate the current problem. This code has been carefully tested for the problem of consistency and precision of the results obtained; mesh independence tests and validation tests have been carefully carried out. To avoid the phenomena of oscillation or divergence of the variables that can appear during the iterative resolution of the equations, a method of underrelaxation has been applied to all the nodal points for the solution fields and the two scalars in order to attenuate the rapid variations of the coefficients between two successive iterations.

\section{Comparisons with Previous Work}

To validate this code a series of test were compared with experimental data of Lebedev et al. [2] and numerical results of Asis Giri et al. [3]. The first comparison is based on the experimental data of Lebedeve et al. [2] in the case of heat and mass transfer in vapor condensation of humid air along a rectangular channel with $20 \mathrm{~mm}$ of wide, $150 \mathrm{~mm}$ of high, $600 \mathrm{~mm}$ of long, inlet temperature $56^{\circ} \mathrm{C}$, inlet pressure $1 \mathrm{~atm}$, and relative humidity $100 \%$. Figure 3 presents the local condensate heat transfer coefficient $h_{L, \text { cond }}$ for different values of mixtures content at the middle of the channel (kg of water vapor per kg of dry air). It is apparent that the results obtained from the present work are in good concordance with those of Lebedev et al. [2]. The second comparison is presented in
Figure 4 which illustrates the dimensionless condensate film profiles throughout the channel. Asis Giri et al. [3] studied the condensation in a vertical channel with: length $L=0.75 \mathrm{~m}$, half-width $H=0.005 \mathrm{~m}$, an inlet temperature $T_{\text {in }}=60^{\circ} \mathrm{C}$, and temperature of the wall $T_{W}=30^{\circ} \mathrm{C}$; the air-vapor mixture is entered with $100 \%$ of humidity at different number of inlet Reynolds and inlet pressure as mentioned in Figure 4. The results presented in this figure show the good agreement compared with the results of Asis Giri et al. [3].

\section{Results and Discussion}

In this study, the values of physical and geometric parameters are chosen as follows: the inlet Reynolds numbers are 1000, 1500 , and 2000; inlet relative humidity of $60 \%, 80 \%$, and $100 \%$; inlet temperatures of $40^{\circ} \mathrm{C}, 60^{\circ} \mathrm{C}$, and $80^{\circ} \mathrm{C}$; inlet pressure of $1 \mathrm{~atm}, 1.5 \mathrm{~atm}$, and $2 \mathrm{~atm}$; temperature difference wall-to-inlet of $\Delta T=T_{\text {in }}-T_{W}=20^{\circ} \mathrm{C}$; and the channel length $L=2 m$ and the half-width $H=0.01 \mathrm{~m}$. The problem studied is supposed axisymmetric.

The important results presented and discussed in this paper are very much interested in detailed profiles of the axial variation of a dimensional velocity, a dimensional temperature, a dimensional mass fraction of vapor, and dimensionless thickness of liquid condensate film to better understand the different transport processes involved in this phase change phenomenon in order to know the parameters favoring condensation in the condensation channels. Particular attention is rewarded to the influence of independent parameters on the variation of $\delta^{*}, N u_{y}$, and $M r$.

The results presented in Figure 5 show the axial variation of the interface dimensionless temperature, interface vapor mass fraction, interfacial mass condensation rate, and the film thickness, which is the air-water vapor mixture entering the canal under the following entry conditions: $\operatorname{Re}_{i n}=2000$, 


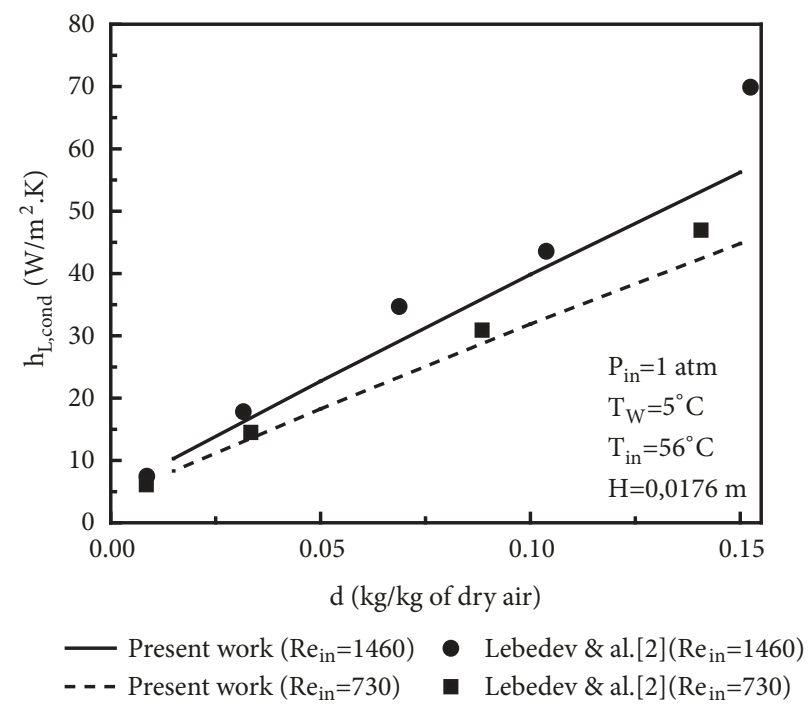

Figure 3: Comparison of a local heat transfer coefficient $h_{L, \text { cond }}$ due to condensation with Lebedev et al. [2].

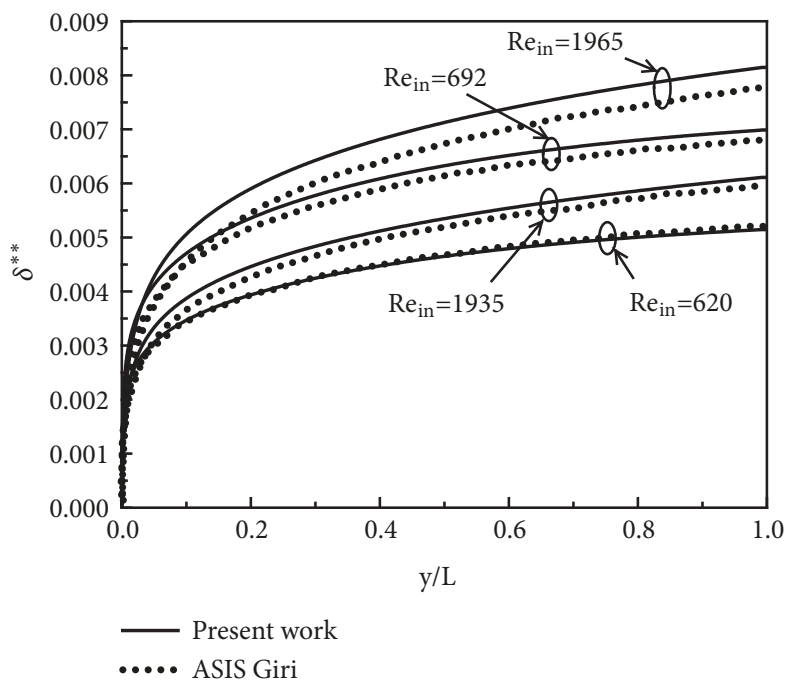

FIgURE 4: Comparison of dimensionless liquid film thickness with Asis Giri et al. [3].

$P_{\text {in }}=1 \mathrm{~atm}, T_{\text {in }}=80^{\circ} \mathrm{C}, R H_{\text {in }}=100 \%$, and $\Delta T=20^{\circ} \mathrm{C}$. Figures 5(a) and 5(b) show the variation of the axial dimensionless temperature and vapor mass fraction at the interface. It is noted that the interface vapor mass fraction decrease axially due to the loss of vapor; this results in a gradual decrease of the steam in the mixture and the profiles have a similar slope throughout the flow; therefore, the interface temperature decrease alongside the channel until reaching the thermodynamic equilibrium between the liquid and mixture phases (i.e., the end of condensation process). This statement is confirmed by Figure 5(c), which indicate that condensation mass flux decreases alongside the channel. The mass condensate rate gradually decreases as the film becomes thicker and practically ceased when the condensation shuts off and the interface temperature became practically almost equal to the temperature of cold wall Figure 5(d).
The results shown in Figure 6 are the profiles of dimensionless velocity, dimensionless temperature, and dimensionless vapor mass fraction at different axial stations of the channel. The entry conditions used for these results are an inlet Reynolds number of $\mathrm{Re}_{i n}=2000$, an inlet temperature of $80^{\circ} \mathrm{C}$, and an inlet relative humidity of $100 \%$. The liquid film region corresponds to $0 \leq \eta \leq 1$ and the mixture region corresponds to $1 \leq \eta \leq 2$. From the dimensionless velocity profile in Figure 6(a), it can be observed that as y increases, the velocity in the mixture attains a parabolic profile, while the velocity in the liquid film increases in the channel. This trend is due to the small transfer of mass from the mixture to the liquid. The mixture flow is losing mass slowly with the condensation process and the liquid film is slowly gaining mass and accelerating. At various sections of the channel, it is found that the mixture velocity decreases from the symmetry 


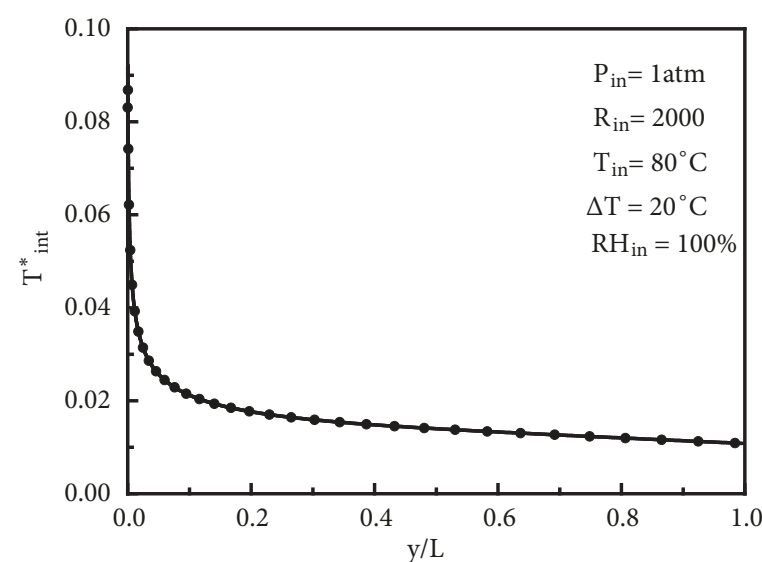

(a)

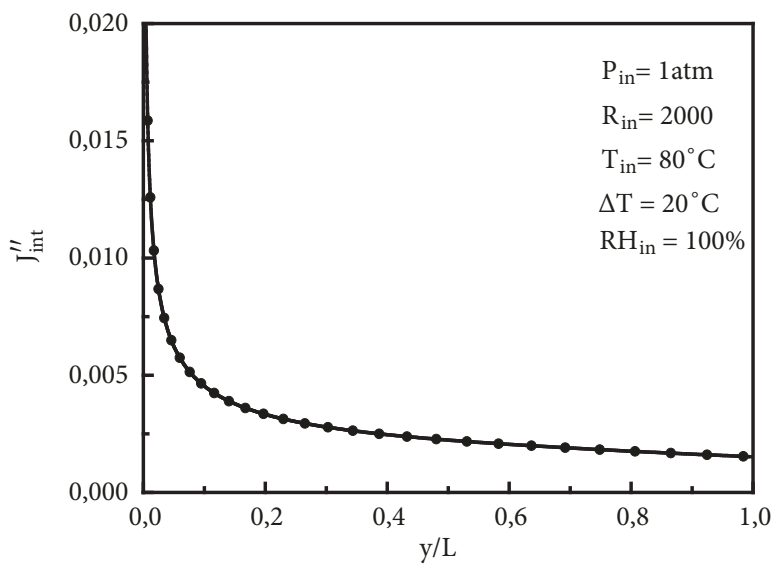

(c)

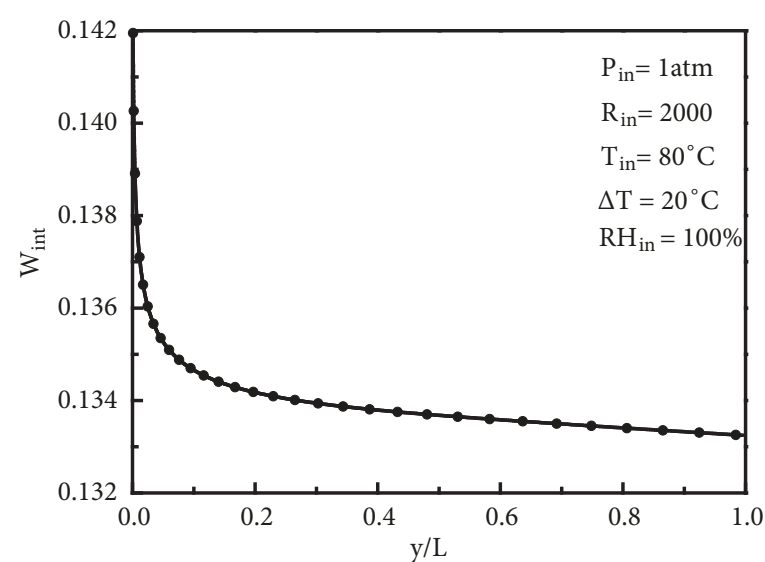

(b)

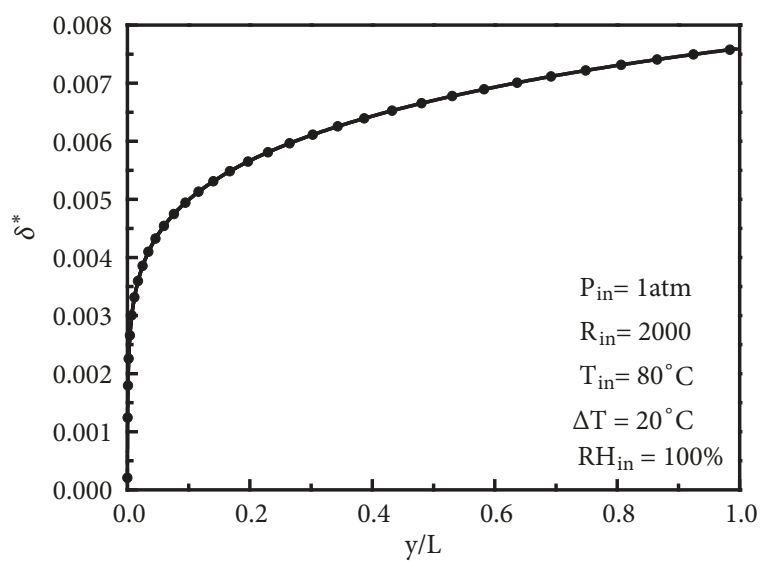

(d)

FIGURE 5: (a) Interface dimensionless temperature, (b) interface vapor mass fraction, (c) interfacial mass condensation rate, and (d) dimensionless film thickness.

axis of the channel to approach a value of the liquid phase at the liquid-vapor interface.

Figure 6(b) shows the profiles of dimensionless temperature in the mixture and liquid regions at different axial positions of the channel. In the liquid regions the temperature profiles are almost linear. This trend is due to the convection terms in the liquid energy equation which are not very significant. It is also noted that liquid temperature $T_{L}^{*}$ (at the interface) is very small at all channel positions shown. This signifies that the interface temperature is very close to the wall temperature (thin film condensation). The temperature in the air-vapor mixture phase $T_{M}^{*}$ starts out at $T_{\text {in }}$ at the channel inlet and appears to approach $T_{W}$ proximate the interface at large values of $y$ (at the exit $y=L$ ). The profiles of temperature and concentration Figures 6(b) and 6(c) in the vapor phase decrease in direction towards the liquidvapor interface and along the flow $\left(T_{\text {in }}\right.$ tends to $T_{\text {int }}$ and $W_{\text {in }}$ tends to $\left.W_{\text {int }}\right)$. The condensation of the steam is accompanied with a decrease in the mass fraction of the steam causing a decrease in the interfacial temperature. Indeed, the interfacial temperature is related to the partial pressure which is also related to the interfacial concentration of the vapor. After analyzing the selected parameters, now we turn our attention on the effect of each parameter on heat and mass transfer during condensation.

5.1. Effect of Changing $R H_{\text {in }}$ and $R e_{i n}$. The effect of changing relative humidity and Reynolds number are presented in Figure 7 . The operating conditions considered in this simulation are inlet pressure $P_{\text {in }}=1 \mathrm{~atm}$, inlet temperature $T_{\text {in }}=80^{\circ} \mathrm{C}$, and inlet-to-wall temperature difference $\Delta T=20^{\circ} \mathrm{C}$. The variation of the liquid film thickness is shown in Figure 7 (a). In this figure, we can see that the slope of film thickness near the inlet region is high due to the large gradient of concentration, followed by a more moderate and substantially linear growth for each inlet Reynolds and relative humidity. For a fixed value of Reynolds number, we observed that the film thickness increases with the relative humidity $R H_{i n}$. This trend is a result of the diminution in inlet air mass fraction with increased $R H_{\text {in }}$ and higher mass of vapor which leads to more condensation and a thicker film. This figure shows also that the film thickness increases with the increase of $\mathrm{Re}_{\text {in }}$ at a fixed relative humidity; this is due to the increase in the inlet mass flow rate when Re increases, which results in a greater amount of condensed vapor. 


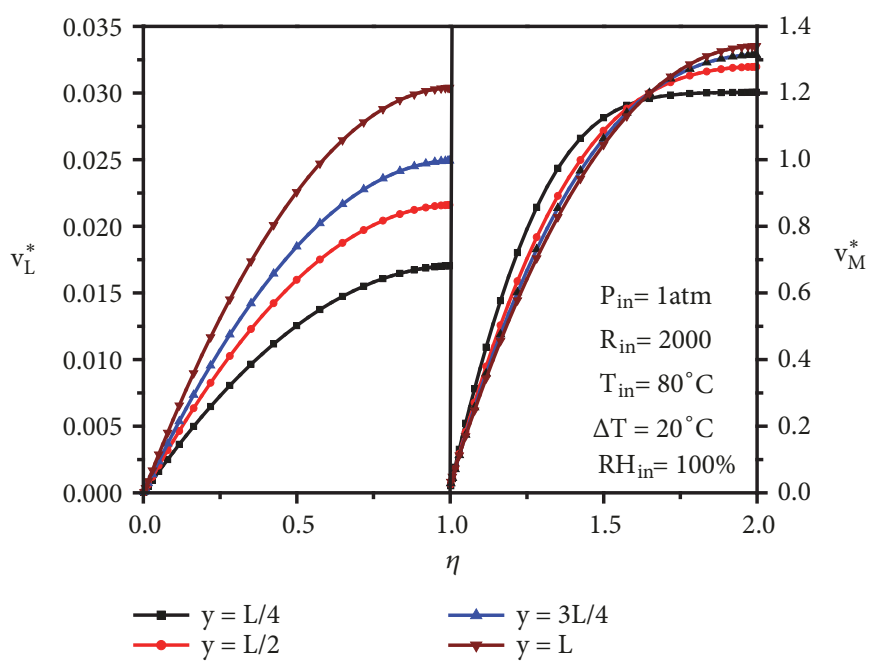

(a)

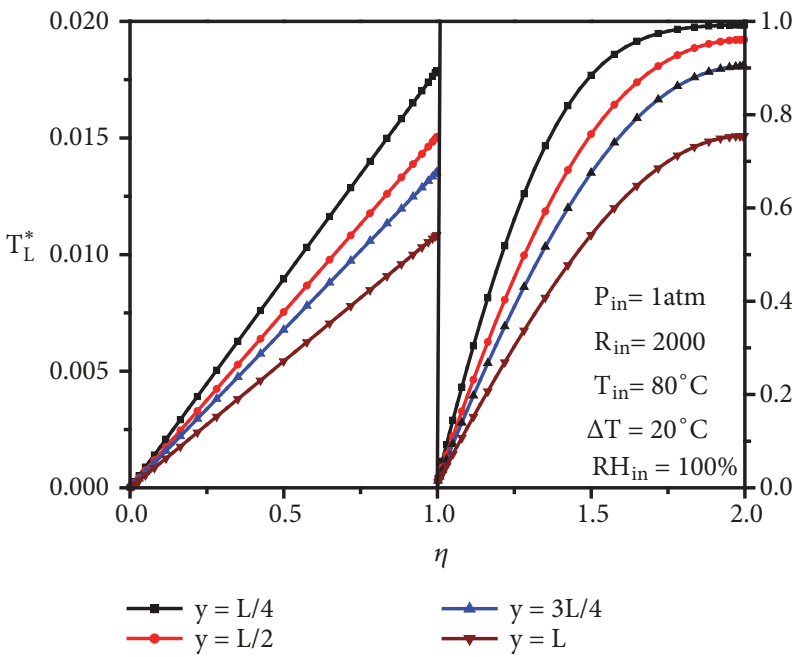

(b)

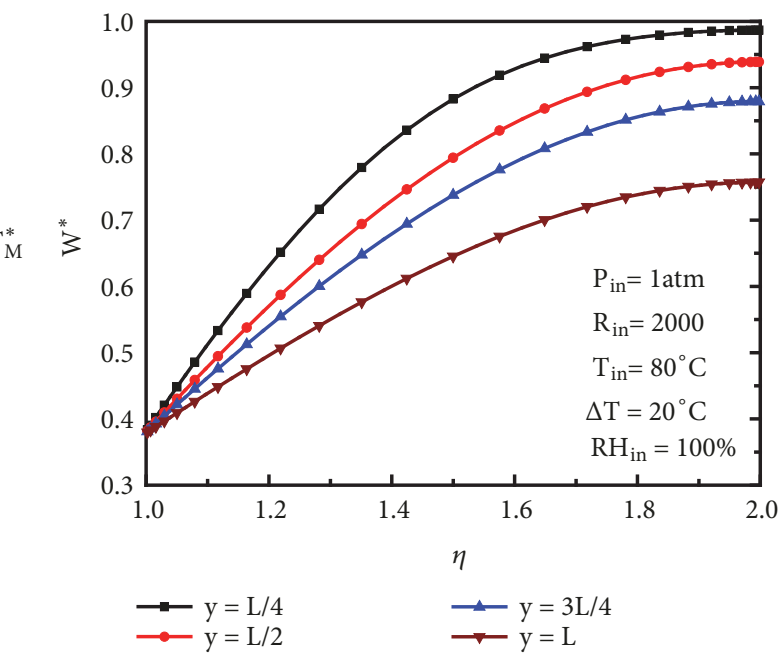

(c)

FIGURE 6: Sample profiles at various axial locations: (a) dimensionless axial velocity, (b) dimensionless temperature, and (c) dimensionless vapor mass fraction.

Figure 7(b) shows that the increasing of the Reynolds number at fixed relative humidity the Nusselt number increases. The thermal flux at the interface increases with increasing Reynolds number, due to the increase of the liquid temperature gradient at the wall and the interface temperature. The total heat flux remains substantially proportional to the mass flow rate of liquid, because it comes mainly from the latent heat of condensation. The increase of Reynolds number is accompanied by a large increasing in the mass flux at the interface which leads to a large increase in the condensation in the superior section of the channel. However, heat transfer along the downward stream flow decreases, thus demonstrating that the convection film condensation of the vapor is accompanied by a decrease in the temperature of the mixture phase. This figure also shows that increasing $R H_{\text {in }}$ leads to higher $N u_{y}$ for a given $\mathrm{Re}_{i n}$ value. This trend is a result of the increasing of the quantity of steam at the entrance of the channel. This trend is coherent with the previous discussion on having more condensation (higher liquid film thickness: Figure 6(a)) for higher $R H_{\text {in }}$.

The accumulated condensate rate is shown in Figure 6(c). It is noted in this figure that the increase in the value of the Reynolds number, which means that an increase in the flow velocity of entry since the diameter of the channel is fixed is accompanied by an increase in the flow rate mass of vapors at the entrance $\dot{m}_{i n}$ and consequently a reduced rate of condensation. This trend is the result of the increase in the Reynolds number which produce high amount of the condensed vapor alongside the channel, especially at the entrance. However, the accumulated condensate rate increases with increasing of relative humidity. This trend is confirmed by the result of Figure 6(a).

5.2. Effect of Changing $T_{i n}$. The effects of changing $T_{\text {in }}$ of the vapor in the condensation process were examined for steam-air at $\mathrm{Re}_{i n}=2000, P_{i n}=1 \mathrm{~atm}$, and $\Delta T=20^{\circ} \mathrm{C}$. 


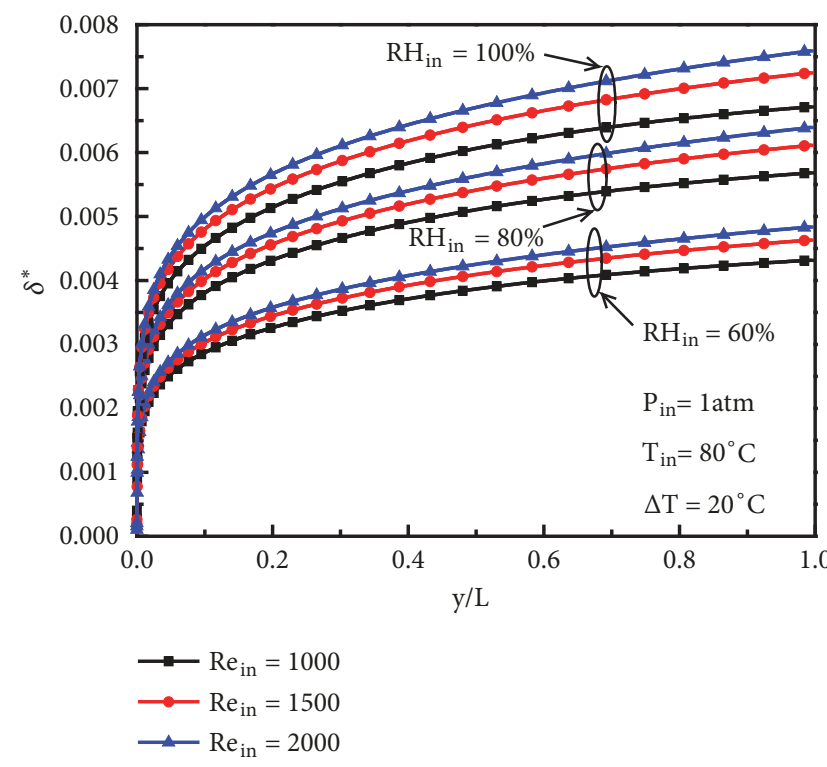

(a)

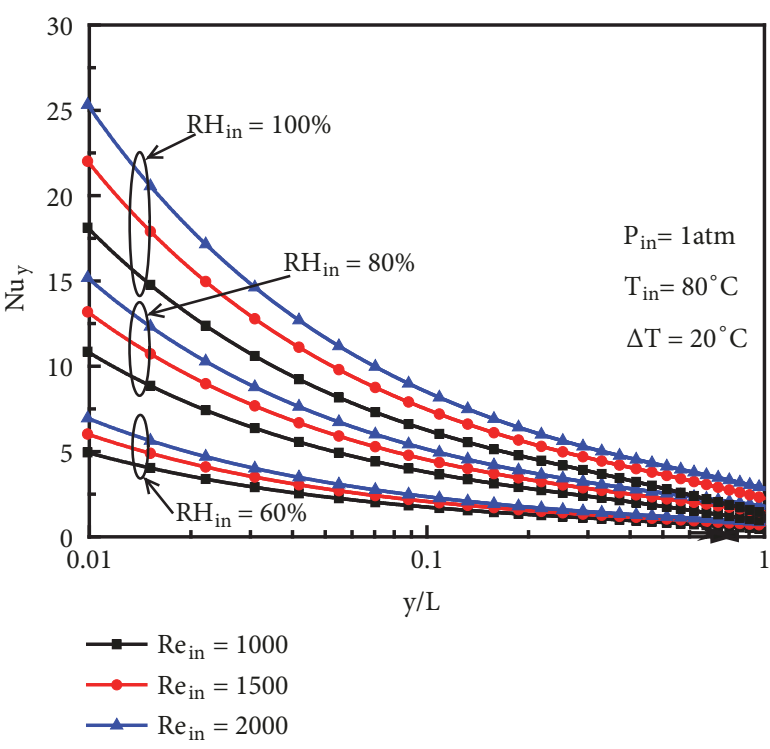

(b)

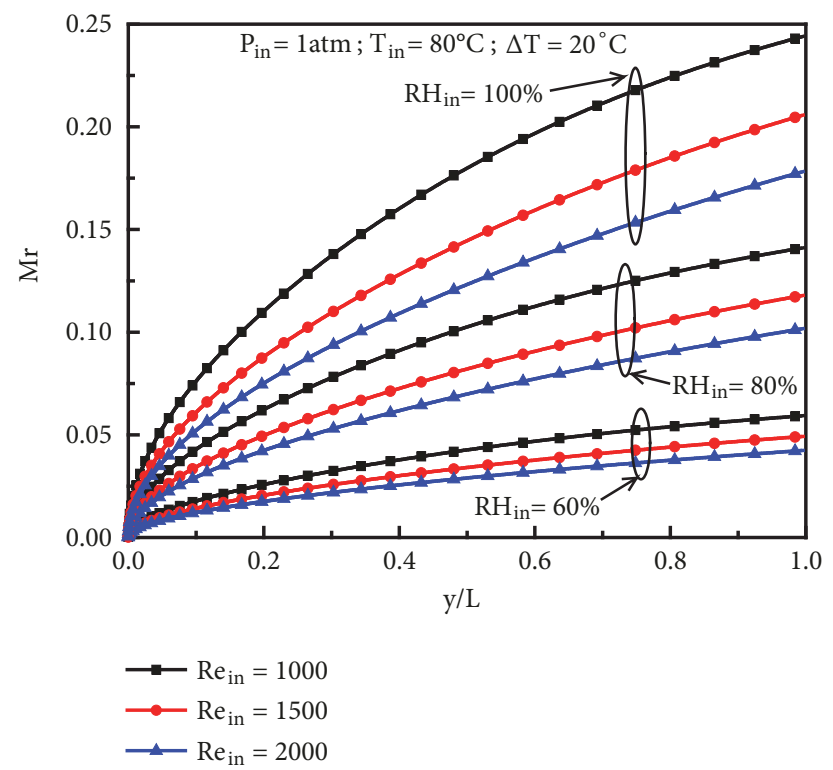

(c)

Figure 7: Axial variations of (a) film thickness, (b) local Nusselt number, and (c) accumulated condensate rate with Reynolds number at different relative humidity.

The results shown in Figure 8(a) present the variation of the film thickness along the downward stream flow for three values of $T_{\text {in }}$ and two values of $R H_{\text {in }}$. These results show that the liquid film thickness increases with increasing $T_{i n}$. This is explained by increasing $T_{i n}$; the concentration of vapor $W_{\text {in }}$ increases; hence the mass flow condensed of vapor increases. Throughout the channel, the film thickness increases gradually with $T_{\text {in }}$ until the end of condensation of the water vapor. At $T_{i n}=40^{\circ} \mathrm{C}$, the film thickness increases rapidly to $y / L=0.2$ after this position; the slope of the film thickness becomes low until the exit of the channel. This can be a result of the small amount of vapor introduced which is completely condensed. Therefore, for a specific inlet temperature (e.g., $T_{\text {in }}=80^{\circ} \mathrm{C}$ ), augmenting inlet relative humidity increases the film thickness. This implies that, from top to bottom of the channel, the concentration of vapor becomes most significant and the film is thicker for higher inlet relative humidity because of the increased inlet mass of vapor (as shown previously form Figure 7). This statement is confirmed by Figure 7(a), which indicate that condensation mass flux increases with an increase the relative humidity. The local Nusselt number variation is shown in Figure 8(b). The Nusselt number is also augmented with the increase in $T_{\text {in }}$ and $R H_{\text {in }}$ due to the increase in condensation rate. At the entrance 


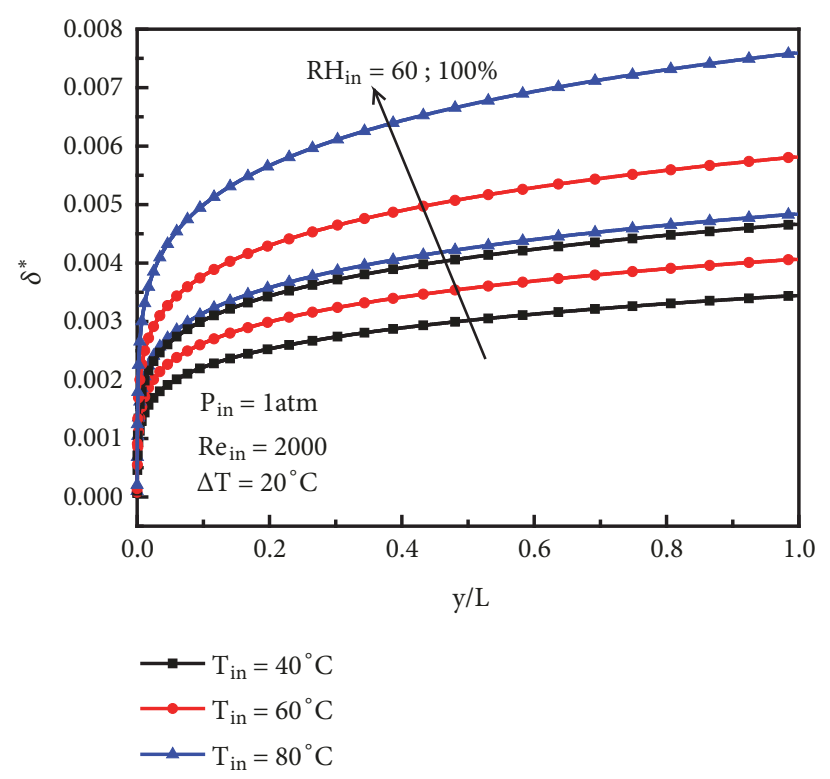

(a)

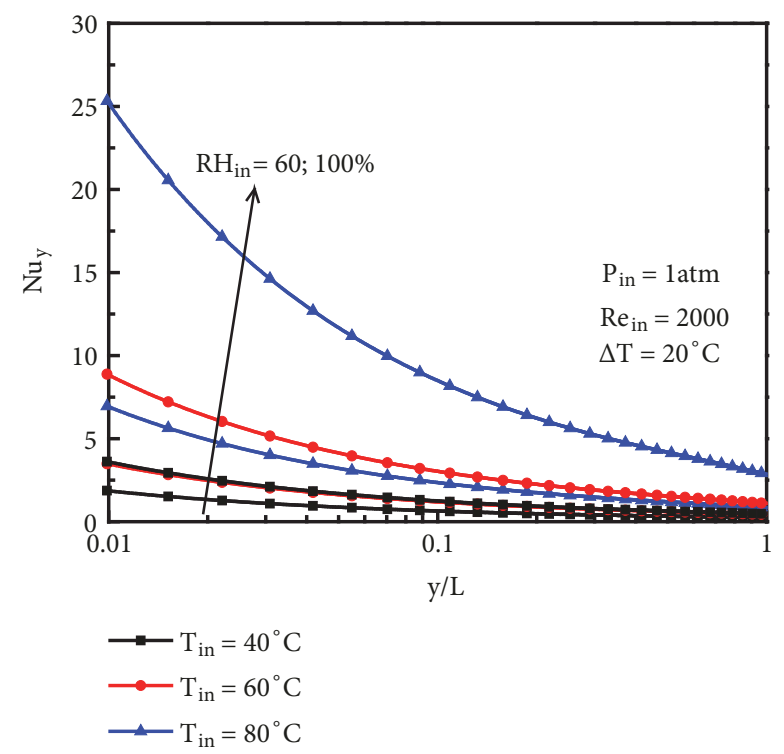

(b)

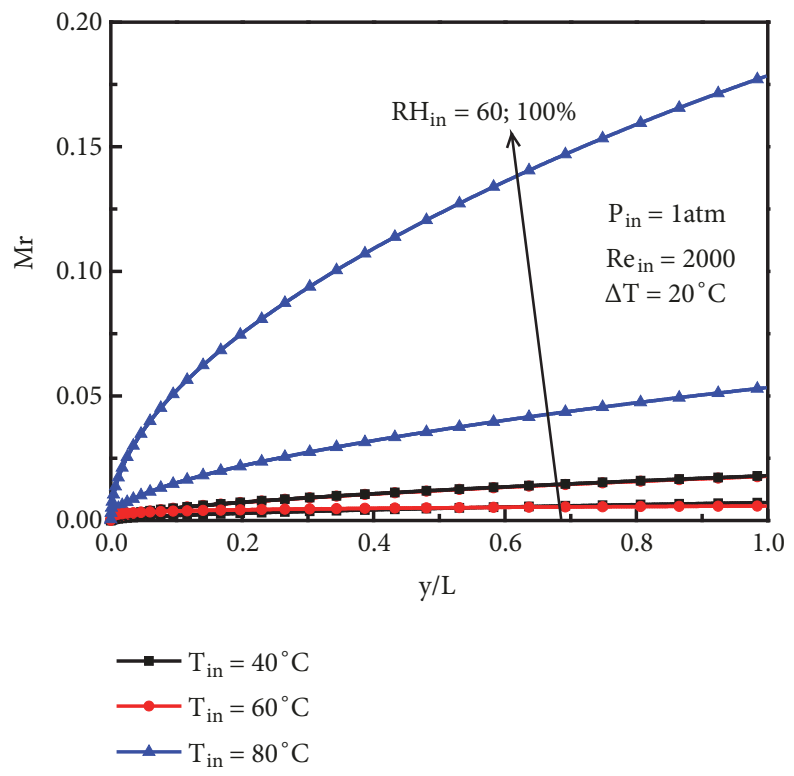

(c)

Figure 8: Axial variations of (a) film thickness, (b) local Nusselt number, and (c) accumulated condensate rate with inlet temperature at different $R H_{\text {in }}$.

of the channel, it is noted that the heat transfer is higher when the inlet temperature is high; then it decreases and becomes very low at the end of the condensation. Figure 8(c) illustrates the accumulated condensed rate of water vapor for different inlet temperatures, by varying the relative humidity. It is noted that the accumulated condensed rate increases with the increasing of $T_{\text {in }}$ and $R H_{\text {in }}$. Indeed, the increase in the mass fraction of the steam causes significant condensation of the water vapor; this was confirmed by the previous figures. On the other hand, for low inlet temperatures and relative humidity of vapor, the accumulated condensed rate increases from top to bottom of the channel until $y / L=0.2$ and becomes constant. For higher inlet temperature $\left(T_{\text {in }}=80^{\circ} \mathrm{C}\right)$, the gradient of the curve is very important compared to low temperature inlet; therefore, the conditions of the end of condensation are not yet achieved.

5.3. Effect of Changing $P_{i n}$. The effect of the pressure inlet on the condensation of vapor was investigated at $\mathrm{Re}_{i n}=$ $2000, T_{\text {in }}=80^{\circ} \mathrm{C}$, and $\Delta T=20^{\circ} \mathrm{C}$, for three values of $P_{\text {in }}(1$, 1.5 , and $2 \mathrm{~atm}$ ), and two values of relative humidity (60 and $100 \%)$. The results obtained in Figure 9(a) show that the film thickness of the condensate decreases as $P_{i n}$ increases. Before examining these results, it would be interesting to discuss 


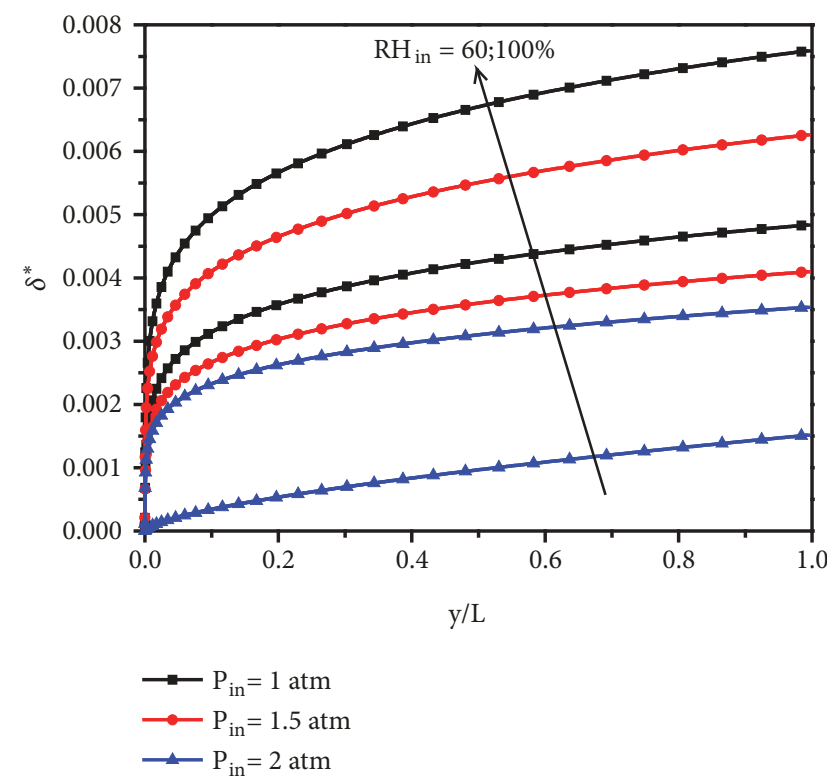

(a)

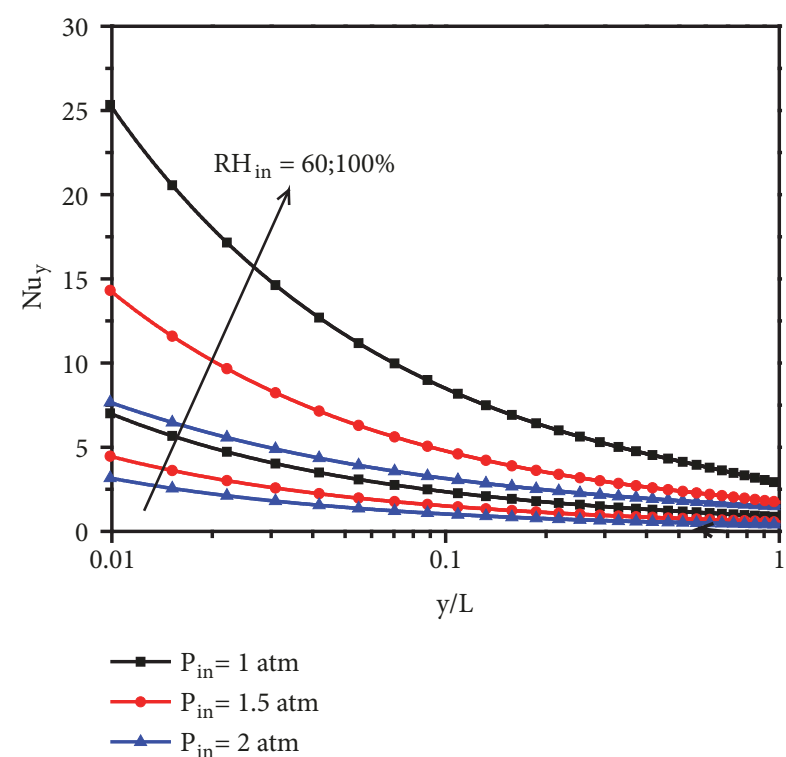

(b)

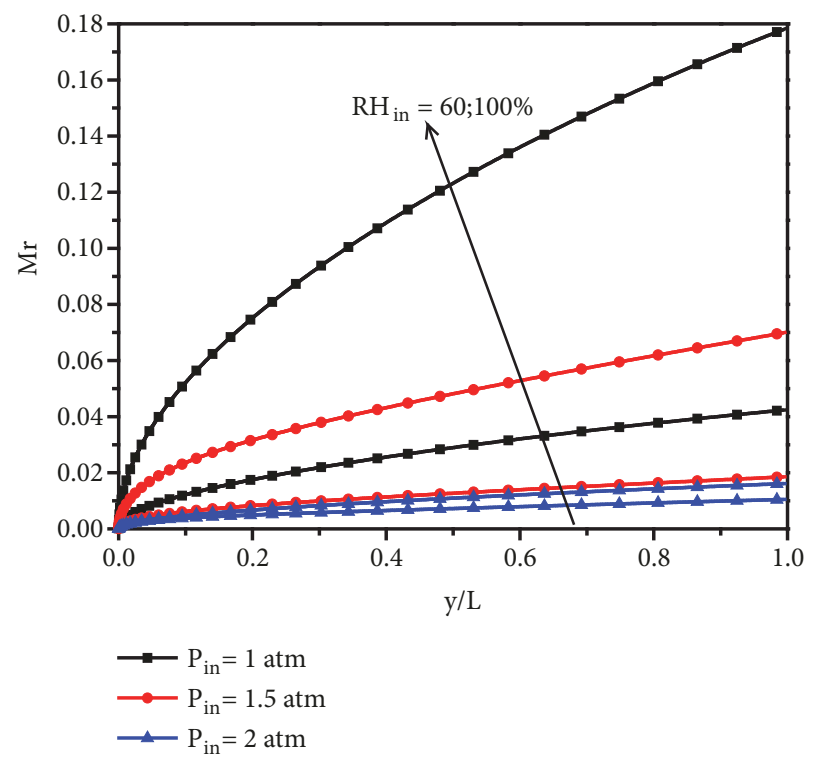

(c)

FIgURE 9: Axial variations of (a) film thickness, (b) local Nusselt number, and (c) accumulated condensate rate with inlet pressure.

the anticipated impact of changing $P_{\text {in }}$ on the condensation process. Increasing $P_{i n}$ for fixed $R H_{\text {in }}$ decreases the mass fraction of steam-air $W_{\text {in }}$ for fixed $\Delta T$. The decrease in $W_{\text {in }}$ leads to a decrease in mass flow rate condensed as $P_{\text {in }}$ increases, and consequently the film thickness of the liquid decreases as $P_{\text {in }}$ increases. This explains that the condensation process is small for the higher inlet pressure at a fixed relative humidity.

In Figure 9(b) we present the effect of $P_{\text {in }}$ on local Nusselt number. These results show that $N u_{y}$ has grown as $P_{\text {in }}$ is increased. This implies that when $P_{\text {in }}$ decreases, the concentration of vapor increases and hence local Nusselt number decreases. This trend is the result of decreasing of
$W_{\text {in }}$ and increasing of the NCG. And during condensation of small concentrations of vapor from a mixture with noncondensing gas, the gas content causes a resistance to heat and mass transfer and consequently thus the decrease in $N u_{y}$. In Figure 9(c) we plot the axial variation of accumulated condensate rate $M r$ versus $y / L$ at various inlet pressures. The result shows that $M r$ increases with decreasing the inlet pressure $P_{\text {in }}$ throughout the channel and takes the higher values for top relative humidity. The effect of relative humidity is very significant as compared to the inlet pressure. This clearly confirms that the increasing of gas in the vapor stream has a very strong effect on the condensation process. 
The accumulation of NCGs at the gas-liquid interface obstructs steam diffusing from the gas-vapor mixture to the liquid film; in addition, since the total pressure remains constant, the accumulation of NCGs also decreases the steam partial pressure at the interface, reducing the saturation temperature and the driving force for steam condensation.

\section{Conclusion}

A finite-volume method has been successfully developed to solve the problem of laminar film condensation flowing downward in a vertical, parallel plate channel. Complete boundary-layer equations for each phase with variable physical properties were considered. The solution method utilizes a fully coupled approach. This coupling approach along with all fundamental balances at the phase interface makes the system of equations extremely difficult to solve. Results were obtained for vapor-air mixtures by specifying the following values at the inlet of the channel: $\Delta T, \operatorname{Re}_{i n}, P_{i n}, T_{i n}$, and $R H_{\text {in }}$. These outcomes include dimensionless velocity and temperature profiles in both phases, dimensionless mass fraction of vapor, the axial variation of dimensionless film liquid thickness, the local Nusselt number, and the accumulated condensate rate. The main conclusions from the study are summarized below:

(i) For fixed input data $\left(\mathrm{Re}_{i n}=2000, P_{\text {in }}=1 \mathrm{~atm}\right.$, $T_{\text {in }}=80^{\circ} \mathrm{C}$, and $\Delta T=20^{\circ} \mathrm{C}$ ), increasing the relative humidity from $60 \%$ to $100 \%$ increases the condensation rate by more than $75 \%$. In addition, for each value of humidity relative the change of $T_{\text {in }}$ from $40^{\circ} \mathrm{C}$ to $80^{\circ} \mathrm{C}$ increases $\mathrm{Mr}$ by more than $88 \%$. On the other hand, the increase in the inlet pressure from $1 \mathrm{~atm}$ to $2 a t m$ and that for fixed $R H_{\text {in }}$ decrease the condensate rate by $90 \%$.

(ii) The film thickness and Nusselt number augmented when increasing the inlet temperature and Reynolds number and when decreasing the inlet pressure. Indeed, for constant operating conditions $\left(\mathrm{Re}_{i n}=\right.$ 2000, $P_{\text {in }}=1 \mathrm{~atm}, T_{\text {in }}=80^{\circ} \mathrm{C}$, and $\Delta T=20^{\circ} \mathrm{C}$ ), the variation of $R H_{\text {in }}$ from $60 \%$ to $100 \%$ increases the liquid film thickness by more than $34 \%$ and increase the local Nusselt number by $70 \%$ in the exit of the channel. Likewise, for constant $R H_{\text {in }}$ the variation of inlet temperature from $40^{\circ} \mathrm{C}$ to $80^{\circ} \mathrm{C}$ increases the liquid film thickness by $36 \%$ and the local Nusselt number by more than $90 \%$ at the channel exit.

(iii) Using higher relative humidity leads to a lower NCG and an elevated the amount for vapor, which results in an improvement of the heat and mass transfer process, for fixed values of operating conditions. The relative humidity was found to have significant effects on the condensation process, so larger relative humidity also leads to more condensation.

The above results could be useful for finding the optimum conditions for different operating parameters to enhance the heat and mass transfer in the process of condensation which is one of the most applicable methods of phase change which is observed in different industrial equipment as well mentioned above.

\section{Nomenclature}

$C_{P}: \quad$ Specific heat $\left[J \cdot \mathrm{kg}^{-1} \cdot \mathrm{K}^{-1}\right]$

D: $\quad$ Mass diffusivity $\left[m^{2} \cdot s^{-1}\right]$

$g: \quad$ Gravitational acceleration $\left[m . s^{-2}\right]$

$H$ : $\quad$ Half of channel spacing $[m]$

$J_{i}^{\prime \prime}: \quad$ Condensation mass flux $\left[\mathrm{kg} \cdot \mathrm{m}^{-2} \cdot \mathrm{s}^{-1}\right]$

$h_{f g}: \quad$ Latent heat $\left[\mathrm{J}_{\mathrm{kg}} \mathrm{kg}^{-1}\right]$

$L: \quad$ Length of plate $[\mathrm{m}]$

$M_{a}: \quad$ Molar mass of air $\left[\mathrm{kg} \cdot \mathrm{mol}^{-1} \cdot \mathrm{K}^{-1}\right]$

Mr: Condensate rate

$\dot{m}$ : Total inlet mass flow $\dot{m}=\rho_{i n} V_{i n} 2 H$

$M_{v}: \quad$ Molar mass of vapor $\left[\mathrm{kg}_{\mathrm{g}} \mathrm{mol}^{-1} \cdot \mathrm{K}^{-1}\right]$

$N u_{y}$ : Local Nusselt number

$P: \quad$ Mixture pressure $[\mathrm{Pa}]\left[\mathrm{kg} \cdot \mathrm{m}^{-2} \cdot \mathrm{s}^{-1}\right]$

$P^{*}$ : Dimensionless pressure

$$
P^{*}=\left(P-P_{\text {in }}\right) / \rho_{\text {in }} V_{\text {in }}^{2}
$$

Re: Reynolds number of the gas stream $\mathrm{Re}_{\text {in }}=V_{\text {in }} 2 H \rho_{\text {in }} / \mu_{\text {in }}$

$R H: \quad$ Relative humidity

$T: \quad$ Temperature $[K]$

$T^{*}: \quad$ Dimensionless temperature $T^{*}=\left(T-T_{W}\right) / \Delta T$

$\Delta T: \quad$ Inlet-to-wall temperature difference

$u^{*}, v^{*}$ : Dimensionless axial velocity components in $\mathrm{x}$ - and $\mathrm{y}$-directions, respectively, $\left[\mathrm{u} / V_{\text {in }}, \mathrm{v} / V_{\text {in }}\right]$

$x, y$ : Axial, cross-stream coordinates, respectively, $[\mathrm{m}]$

$V_{\text {in }}$ : Inlet velocity calculated from Reynolds

$x^{*}, y^{*}$ : Dimensionless coordinates in $\mathrm{x}$ - and $y$-directions, respectively, $[x / H],[y / H]$

W: $\quad$ Vapor mass fraction

$W^{*}$ : Dimensionless vapor mass fraction $W^{*}=W / W_{\text {in }}$

\section{Greek Symbols}

$\rho: \quad$ Density $\left[\mathrm{kg} \cdot \mathrm{m}^{-3}\right]$

$\mu: \quad$ Dynamic viscosity $\left[\mathrm{kg} \cdot \mathrm{m}^{-1} \mathrm{~s}^{-1}\right]$

$\lambda$ : Thermal conductivity $\left[w \cdot m^{-1} K^{-1}\right]$

$\delta$ : Condensate layer thickness $[m]$

$\delta^{*}$ : Dimensionless condensate layer thickness $[\delta / H]$

$\delta^{* *}$ : Dimensionless condensate layer thickness $[\delta / 2 H]$

$\omega$ : Specific humidity

$\chi, \eta$ : Axial, cross-stream transformed coordinates, respectively

Subscripts

a: Air

in: Inlet

int: Interface liquid-vapor 
$L:$ Liquid

$M$ : Air-water vapor mixture

$W$ : Wall.

\section{Data Availability}

No data were used to support this study.

\section{Conflicts of Interest}

The authors declare that they have no conflicts of interest.

\section{References}

[1] W. Nusselt, "The condensation of steam on cooled surfaces," Zeitschrift des Vereines Deutscher Ingenieure, vol. 60, pp. 541575, 1916.

[2] P. D. Lebedev, A. M. Baklastov, and Z. F. Sergazin, "Aerodynamics, heat and mass transfer in vapour condensation from humid air on a flat plate in a longitudinal flow in asymmetrically cooled slot," International Journal of Heat and Mass Transfer, vol. 12, no. 8, pp. 833-841, 1969.

[3] A. Giri, D. Bhuyan, and B. Das, "A study of mixed convection heat transfer with condensation from a parallel plate channel," International Journal of Thermal Sciences, vol. 98, pp. 165-178, 2015.

[4] F. Dobran and R. S. Thorsen, "Forced flow laminar filmwise condensation of a pure saturated vapor in a vertical tube," International Journal of Heat and Mass Transfer, vol. 23, no. 2, pp. 161-177, 1980.

[5] Q. T. Le, S. J. Ormiston, and H. M. Soliman, "A closed-form solution for laminar film condensation from quiescent pure vapours on curved vertical walls," International Journal of Heat and Mass Transfer, vol. 73, pp. 834-838, 2014.

[6] Q. T. Le, S. J. Ormiston, and H. M. Soliman, "A closed-form solution for laminar film condensation from downward pure vapour flow in vertical tubes," International Communications in Heat and Mass Transfer, vol. 81, pp. 141-148, 2017.

[7] M. K. Groff, S. J. Ormiston, and H. M. Soliman, "Analysis of laminar film condensation from vapor-gas mixtures in vertical tubes," in Proceedings of the Third International Symposium on Two-Phase Flow Modelling and Experimentation, Pisa, Italy, 2004.

[8] Y. E. Hammami, M. Feddaoui, T. Mediouni, and A. Mir, "Numerical study of condensing a small concentration of vapour inside a vertical tube," Heat and Mass Transfer, vol. 48, no. 9, pp. 1675-1685, 2012.

[9] F. Hassaninejadfarahani, M. K. Guyot, and S. J. Ormiston, "Numerical analysis of mixed-convection laminar film condensation from high air mass fraction steam-air mixtures in vertical tubes," International Journal of Heat and Mass Transfer, vol. 78, pp. 170-180, 2014.

[10] V. Dharma Rao, V. Murali Krishna, K. V. Sharma, and P. V. J. M. Rao, "Convective condensation of vapor in the presence of a non-condensable gas of high concentration in laminar flow in a vertical pipe," International Journal of Heat and Mass Transfer, vol. 51, no. 25-26, pp. 6090-6101, 2008.

[11] E. C. Siow, S. J. Ormiston, and H. M. Soliman, "A two-phase model for laminar film condensation from steam-air mixtures in vertical parallel-plate channels," Heat and Mass Transfer, vol. 40, no. 5, pp. 365-375, 2004.
[12] E. C. Siow, S. J. Ormiston, and H. M. Soliman, “Two-phase modelling of laminar film condensation from vapour-gas mixtures in declining parallel-plate channels," International Journal of Thermal Sciences, vol. 46, no. 5, pp. 458-466, 2007.

[13] V. D. Rao, V. M. Krishna, P. K. Sharma, and K. V. Sharma, "Convective condensation of vapour in laminar flow in a vertical parallel plate channel in the presence of a high concentration non-condensable gas," Journal of Heat Transfer, vol. 131, Article ID 011502, 2009.

[14] D. Hammoudi, A. Benabdesselam, A. Azzi, and M. A. Kassim, "Numerical modeling of steam condensation in vertical channel in presence of noncondensable gas," International Journal of Thermal Sciences, vol. 126, pp. 263-271, 2018.

[15] A. Charef, M. Feddaoui, M. Najim, and H. Meftah, "Liquid film condensation from water vapour flowing downward along a vertical tube," Desalination, vol. 409, pp. 21-31, 2017.

[16] K. Zine-Dine, Y. El Hammami, R. Mir, T. Mediouni, and S. Armou, "Effect of the non-condensable gas type during condensation of water vapor," Thermal Science, vol. 21, no. 6, pp. 2457-2468, 2017.

[17] K. Zine-Dine et al., "Numerical study of laminar film condensation inside a vertical tube subjected to wall non uniform heat flux," International Journal of Enhanced Research in Science, Technology \& Engineering, vol. 5.2, 2016.

[18] X. Wu, F. Chu, Y. Zhu, and Q. Li, "Vapor free convection film condensation heat transfer in the presence of non-condensable gases with smaller molecular weights than the vapor," Applied Thermal Engineering, vol. 130, pp. 1611-1618, 2018.

[19] Y.-S. S. Chin, Numerical solution of the complete two-phase model for laminar film condensation with a non-condensable gas [Thesis], University of Manitoba, 1995.

[20] S. V. Patankar, Numerical Heat Transfer and Fluid Flow, Hemisphere Publishing, Washington, DC, USA, 1980. 


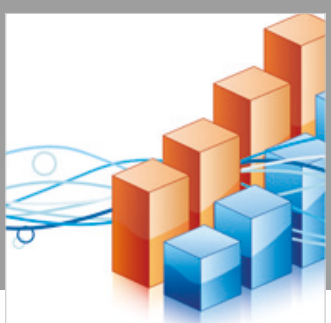

Advances in

Operations Research

\section{-n-m}
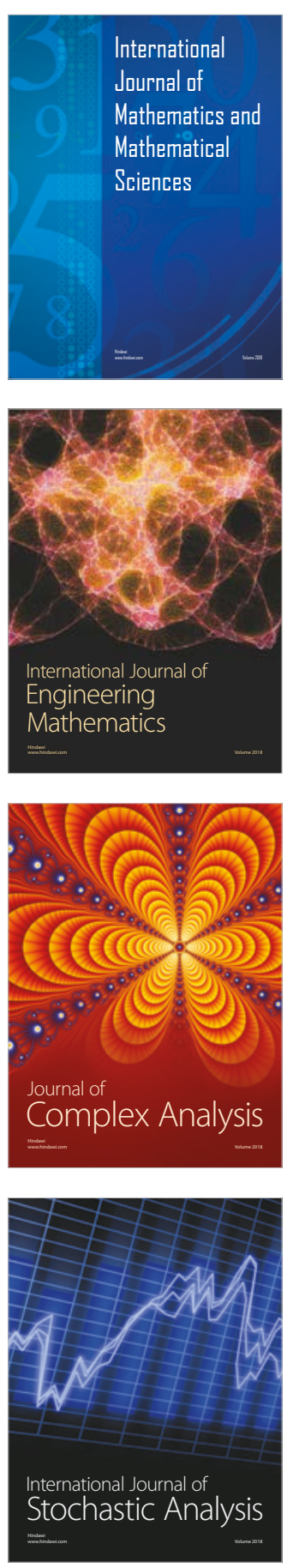
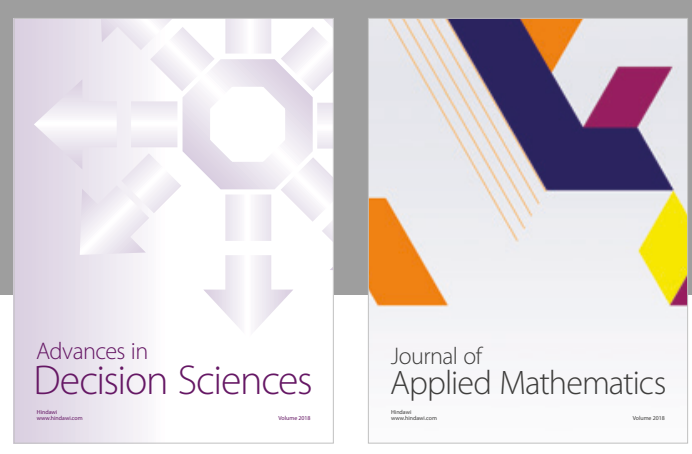

Journal of

Applied Mathematics
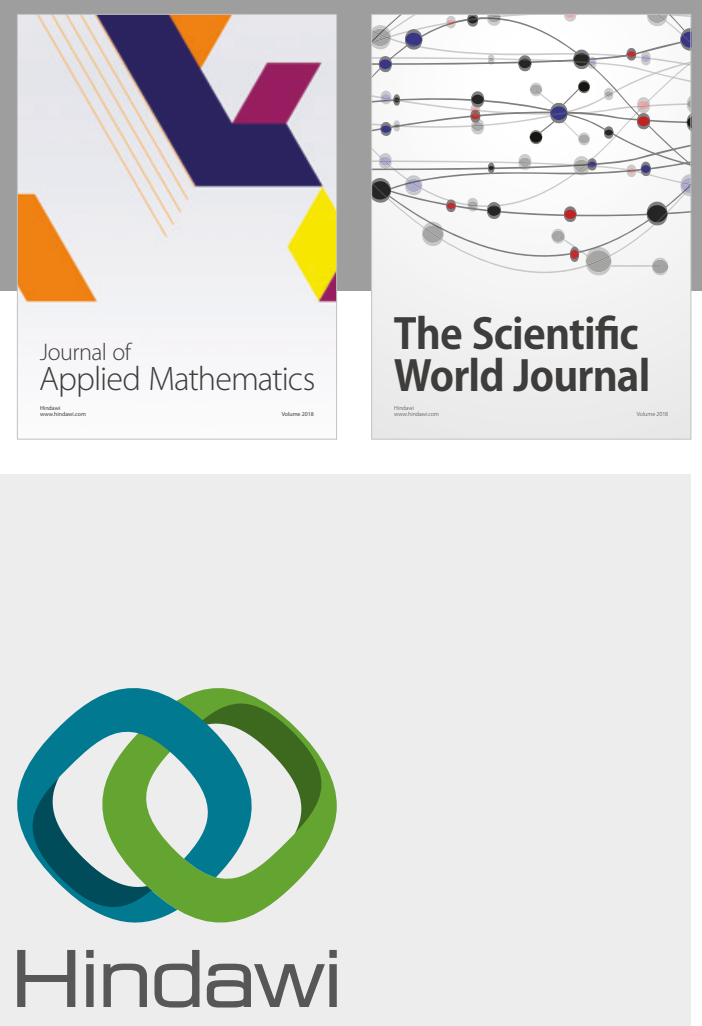

Submit your manuscripts at

www.hindawi.com

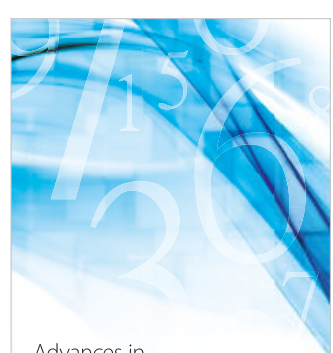

Advances in
Numerical Analysis
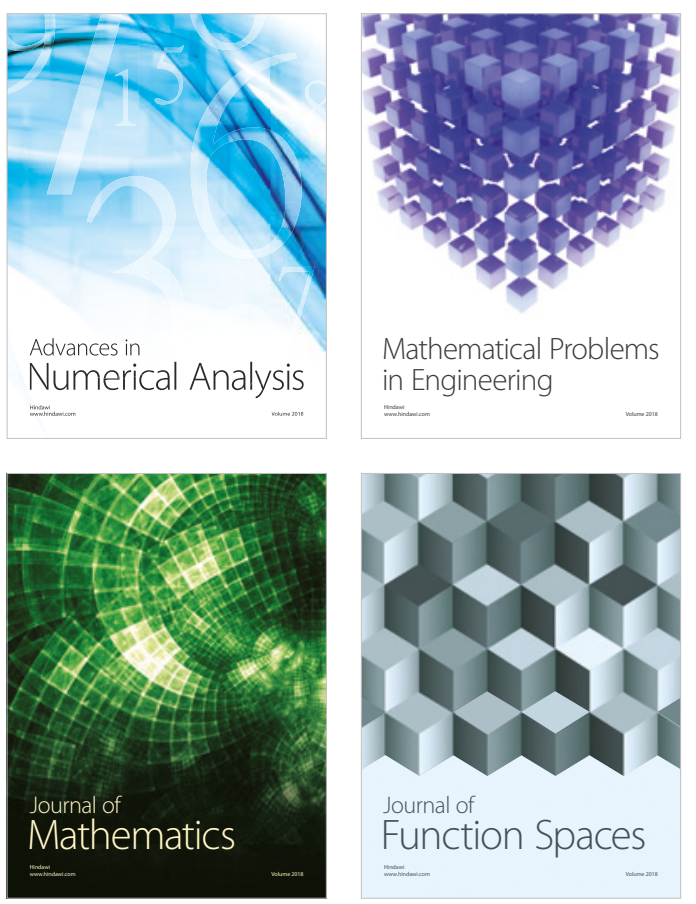

Mathematical Problems in Engineering

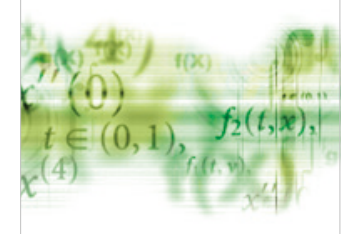

International Journal of

Differential Equations

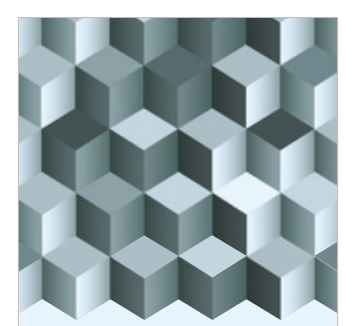

Journal of

Function Spaces

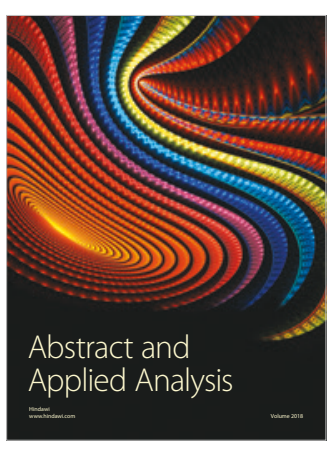

The Scientific

World Journal

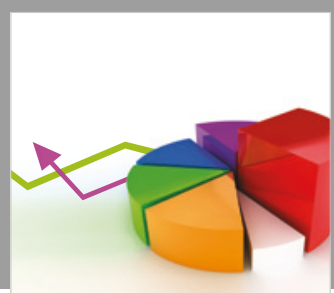

Journal of

Probability and Statistics
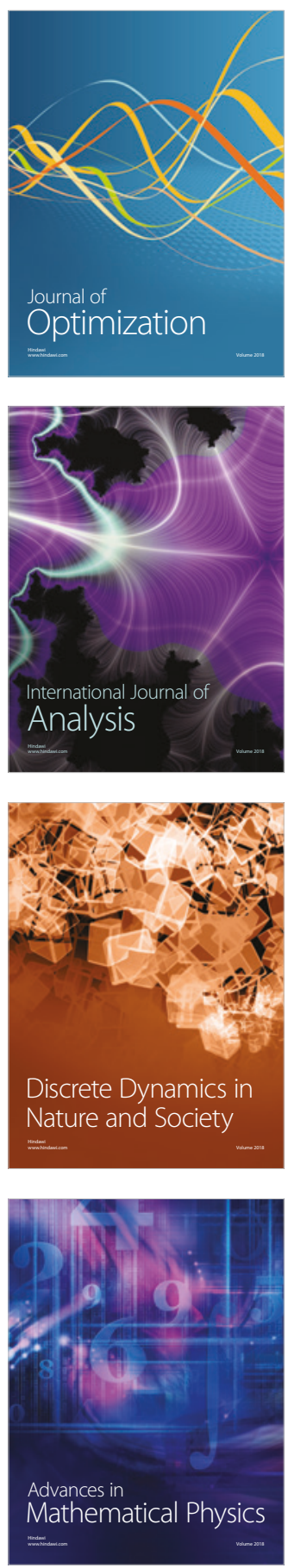